\title{
Article
}

\section{Hydrogen Storage: Thermodynamic Analysis of Alkyl-Quinolines and Alkyl-Pyridines as Potential Liquid Organic Hydrogen Carriers (LOHC)}

\author{
Sergey P. Verevkin ${ }^{1,2, * \mathbb{D}}$, Sergey P. Safronov ${ }^{2}$, Artemiy A. Samarov ${ }^{3} \mathbb{C}$ and Sergey V. Vostrikov ${ }^{2}$ \\ 1 Department of Physical Chemistry and Faculty of Interdisciplinary Research, Competence Centre CALOR, \\ University of Rostock, 18051 Rostock, Germany \\ 2 Chemical Department, Samara State Technical University, 443100 Samara, Russia; \\ safronovsp@yandex.ru (S.P.S.); vosser@mail.ru (S.V.V.) \\ 3 Institute of Chemistry, Saint Petersburg State University, 198504 Saint Petersburg, Russia; samarov@yandex.ru \\ * Correspondence: sergey.verevkin@uni-rostock.de
}

check for

updates

Citation: Verevkin, S.P.; Safronov, S.P.; Samarov, A.A.; Vostrikov, S.V. Hydrogen Storage: Thermodynamic Analysis of Alkyl-Quinolines and Alkyl-Pyridines as Potential Liquid Organic Hydrogen Carriers (LOHC). Appl. Sci. 2021, 11, 11758. https:// doi.org/10.3390/app112411758

Received: 15 November 2021 Accepted: 8 December 2021

Published: 10 December 2021

Publisher's Note: MDPI stays neutral with regard to jurisdictional claims in published maps and institutional affiliations.

Copyright: (c) 2021 by the authors. Licensee MDPI, Basel, Switzerland. This article is an open access article distributed under the terms and conditions of the Creative Commons Attribution (CC BY) license (https:// creativecommons.org/licenses/by/ $4.0 /)$.

\begin{abstract}
The liquid organic hydrogen carriers (LOHC) are aromatic molecules, which can be considered as an attractive option for the storage and transport of hydrogen. A considerable amount of hydrogen up to 7-8\% wt. can be loaded and unloaded with a reversible chemical reaction. Substituted quinolines and pyridines are available from petroleum, coal processing, and wood preservation, or they can be synthesized from aniline. Quinolines and pyridines can be considered as potential LOHC systems, provided they have favorable thermodynamic properties, which were the focus of this current study. The absolute vapor pressures of methyl-quinolines were measured using the transpiration method. The standard molar enthalpies of vaporization of alkyl-substituted quinolines and pyridines were derived from the vapor pressure temperature dependencies. Thermodynamic data on vaporization and formation enthalpies available in the literature were collected, evaluated, and combined with our own experimental results. The theoretical standard molar gas-phase enthalpies of formation of quinolines and pyridines, calculated using the quantum-chemical G4 methods, agreed well with the evaluated experimental data. Reliable standard molar enthalpies of formation in the liquid phase were derived by combining high-level quantum chemistry values of gas-phase enthalpies of formation with experimentally determined enthalpies of vaporization. The liquid-phase hydrogenation/dehydrogenation reaction enthalpies of alkyl-substituted pyridines and quinolines were calculated and compared with the data for other potential liquid organic hydrogen carriers. The comparatively low enthalpies of reaction make these heteroaromatics a seminal LOHC system.
\end{abstract}

Keywords: quinoline derivatives; LOHC; vapor pressure measurements; enthalpy of vaporization; enthalpy of formation; quantum-chemical calculations

\section{Introduction}

The liquid organic hydrogen carriers (LOHC) systems are considered as an attractive option for the storage and transport of hydrogen and enable the gradual transition from fossil fuels to a $\mathrm{CO}_{2}$ emission-free energy supply for both mobile and stationary applications. Hydrogen can be charged in LOHC and reversibly discharged with considerable amounts of hydrogen up to 6-7\% wt. [1]. The LOHC-based energy storage is a challenging technology that requires research and development efforts to optimize its performance to a commercially attractive level. There is no shortage of ideas for suitable candidates for the LOHC systems. For example, the reversible hydrogenation/dehydrogenation reactions of substituted pyridines or quinolines according to Figure 1 could be interesting, since the main sources of pyridines and quinolines include petroleum, coal processing, wood preservation and shale oil, or they can be synthesized from anilines [2]. Provided that pyridines and quinolines have favorable thermodynamic properties, they could be 
considered as a potential LOHC system. Indeed, the gravimetric hydrogen storage capacities are $7.5 \% \mathrm{wt}$. for reaction $1,6.3 \% \mathrm{wt}$. for reaction 2 , and $5.4 \% \mathrm{wt}$. for reaction 3 . Moreover, most of these compounds are low viscose liquids at ambient temperatures (e.g., the melting point and the dynamic viscosity of pyridine $(236 \mathrm{~K}$ and $0.6 \mathrm{cP})$, quinoline $(256 \mathrm{~K}$ and $3.0 \mathrm{cP}), 2$-methyl-pyridine (206 K and $0.8 \mathrm{cP})$, 4-methyl-pyridine (277 K and $0.9 \mathrm{cP}), 2$-methyl-qionoline ( $270 \mathrm{~K}$ and $4.3 \mathrm{cP})$, and 4-methyl-quinoline $(283 \mathrm{~K}$ and $6.2 \mathrm{cP})$ ). These thermophysical properties make the pyridines and quinolines attractive as potential LOHC. The 2-phenylquinoline with a melting temperature of $355.9 \mathrm{~K}$ is a technologically less attractive compound, but it can capture and release 8 moles of hydrogen.<smiles></smiles><smiles>Cc1ccc2ccccc2n1</smiles><smiles>[Z]C1CCC2CCCCC2NC1[R]</smiles><smiles>c1ccc(-c2ccc3ccccc3n2)cc1</smiles><smiles>O[C+]1CCCCC1C1CCC2CCCCC2N1</smiles>

Figure 1. Hydrogenation/dehydrogenation reactions of substituted pyridines or quinolines.

The general lack of thermochemical data for participants of reactions 1-3 (Figure 1) prevents the analysis of the thermodynamic feasibility for these possible LOHC systems.

The development of experimental and theoretical methods for measuring and evaluating thermochemical properties of organic compounds is the long-term goal of our laboratory in Rostock. The focus of this work was on the evaluation of thermochemical properties (vapor pressures, standard molar vaporization enthalpies, $\Delta_{1}^{\mathrm{g}} H_{\mathrm{m}}^{\mathrm{o}}$, and standard molar enthalpies of formation, $\Delta_{\mathrm{f}} H_{\mathrm{m}}^{\mathrm{o}}$ ) of participants of reactions 1 to 3 . These data are essential for the thermodynamic analysis of LOHC systems based on pyridine and quinoline derivatives.

\section{Materials and Methods}

Commercially available samples of methyl-quinolines have been used in this work (see Table S1). They were additionally purified by the fractional distillation. Purities were determined using a gas chromatograph equipped with a capillary column HP-5 and a flame ionization detector. No impurities (greater than 0.0004 mass fraction) were detected in samples used for vapor pressure measurements. Vapor pressures of methylquinolines at different temperatures were measured by using the transpiration method $[3,4]$. The standard molar enthalpies of vaporization, $\Delta_{1}^{\mathrm{g}} H_{\mathrm{m}}^{\mathrm{o}}$, were derived from the temperature dependences of vapor pressures. The quantum-chemical composite method G4 [5] from Gaussian 16 software [6] was used for calculations of enthalpies $\mathrm{H}_{298}$-values, which were finally converted to the $\Delta_{\mathrm{f}} H_{\mathrm{m}}^{\mathrm{o}}(\mathrm{g})$ and discussed. Short descriptions of experimental and theoretical techniques applied in this work are given in ESI (Electronic Supporting Information). 


\section{Results and Discussion}

\subsection{Absolute Vapor Pressures and Thermodynamics of Vaporization}

The experimental vapor pressures, $p_{i}$, for 3-methyl- and 4-methyl-quinolines and their temperature dependence were measured by transpiration. Results of the transpiration method for the quinoline derivatives are given in Table 1.

Table 1. Results of transpiration method for quinoline derivatives: absolute vapor pressures $p_{i}$, standard $\left(p^{\mathrm{o}}=0.1 \mathrm{MPa}\right)$ molar vaporization enthalpies and standard $\left(p^{\mathrm{o}}=0.1 \mathrm{MPa}\right)$ molar vaporization entropies.

\begin{tabular}{|c|c|c|c|c|c|c|c|c|}
\hline $\begin{array}{r}T / \\
\mathrm{K}^{\mathrm{a}}\end{array}$ & $\begin{array}{c}m / \\
m^{b}\end{array}$ & $\begin{array}{l}V\left(\mathrm{~N}_{2}\right)^{\mathrm{c}} / \\
\mathrm{dm}^{3}\end{array}$ & $\begin{array}{l}T_{\mathrm{a}} / \\
\mathrm{K}^{\mathrm{d}}\end{array}$ & $\begin{array}{c}\text { Flow/ } \\
\mathrm{dm}^{3} \cdot \mathrm{h}^{-1}\end{array}$ & $\begin{array}{c}p / \\
P^{\prime} e^{e}\end{array}$ & $\begin{array}{l}u(p) / \\
\operatorname{Pa}^{f}\end{array}$ & $\begin{array}{c}\Delta_{1}^{\mathrm{g}} H_{\mathrm{m}}^{\mathrm{o}}(\mathrm{T})^{\mathrm{g} /} \\
\mathrm{kJ} \cdot \mathrm{mol}^{-1}\end{array}$ & $\begin{array}{c}\Delta_{1}^{\mathrm{g}} S_{\mathrm{m}}^{\mathrm{o}}(\mathrm{T})^{\mathrm{h}} \\
\mathrm{J} \mathrm{K}^{-1} \mathrm{~mol}^{-1}\end{array}$ \\
\hline \multicolumn{9}{|c|}{ 3-methyl-quinoline: $\Delta_{\mathrm{l}}^{\mathrm{g}} H_{\mathrm{m}}^{\mathrm{o}}(298.15 \mathrm{~K})=(63.7 \pm 0.5) \mathrm{kJ} \cdot \mathrm{mol}^{-1}$} \\
\hline \multicolumn{9}{|c|}{$\ln \left(p_{i} / p_{r e f}\right)=\frac{277.3}{R}-\frac{79948.1}{R T}-\frac{54.4}{R} \ln \frac{T}{298.15} ; p_{\text {ref }}=1 \mathrm{~Pa}$} \\
\hline 288.2 & 0.71 & 10.12 & 295.2 & 4.05 & 1.22 & 0.04 & 64.3 & 129.0 \\
\hline 292.2 & 0.61 & 5.940 & 295.2 & 4.05 & 1.76 & 0.05 & 64.1 & 128.2 \\
\hline 295.2 & 0.82 & 6.075 & 295.2 & 4.05 & 2.32 & 0.06 & 63.9 & 127.8 \\
\hline 298.2 & 0.67 & 3.915 & 295.2 & 4.05 & 2.96 & 0.08 & 63.7 & 127.1 \\
\hline 301.2 & 0.71 & 3.038 & 295.2 & 4.05 & 4.03 & 0.11 & 63.6 & 127.0 \\
\hline 304.2 & 0.90 & 3.038 & 295.2 & 4.05 & 5.09 & 0.15 & 63.4 & 126.3 \\
\hline 307.2 & 1.00 & 2.700 & 295.2 & 4.05 & 6.35 & 0.18 & 63.2 & 125.5 \\
\hline 310.4 & 1.00 & 2.025 & 295.2 & 4.05 & 8.48 & 0.24 & 63.1 & 125.3 \\
\hline 313.2 & 0.95 & 1.620 & 295.2 & 4.05 & 10.09 & 0.28 & 62.9 & 124.4 \\
\hline 316.2 & 0.91 & 1.213 & 295.2 & 2.02 & 12.90 & 0.35 & 62.7 & 124.0 \\
\hline 319.2 & 0.94 & 1.013 & 295.2 & 4.05 & 15.96 & 0.42 & 62.6 & 123.4 \\
\hline 322.4 & 0.88 & 0.741 & 295.2 & 2.02 & 20.24 & 0.53 & 62.4 & 122.9 \\
\hline 325.2 & 1.01 & 0.674 & 295.2 & 2.02 & 25.77 & 0.67 & 62.3 & 122.8 \\
\hline 328.2 & 1.24 & 0.674 & 295.2 & 2.02 & 31.43 & 0.81 & 62.1 & 122.2 \\
\hline 331.2 & 1.18 & 0.529 & 295.2 & 1.22 & 38.12 & 0.98 & 61.9 & 121.6 \\
\hline 334.2 & 1.13 & 0.417 & 295.2 & 1.22 & 46.35 & 1.18 & 61.8 & 121.0 \\
\hline 337.2 & 0.98 & 0.305 & 295.2 & 1.22 & 54.90 & 1.40 & 61.6 & 120.3 \\
\hline 340.2 & 1.24 & 0.315 & 295.2 & 1.22 & 67.13 & 1.70 & 61.4 & 119.9 \\
\hline \multicolumn{9}{|c|}{ 4-methyl-quinoline: $\Delta_{\mathrm{l}}^{\mathrm{g}} H_{\mathrm{m}}^{\mathrm{o}}(298.15 \mathrm{~K})=(64.1 \pm 0.4) \mathrm{kJ} \cdot \mathrm{mol}^{-1}$} \\
\hline & & & $\ln ($ & $=\frac{276.9}{R}$ & $6-\frac{54}{R}$ & $\frac{1}{5} ; p_{\text {ref }}$ & & \\
\hline 294.2 & 1.19 & 11.54 & 293.2 & 4.47 & 1.76 & 0.05 & 64.3 & 127.6 \\
\hline 298.2 & 0.95 & 6.524 & 296.2 & 4.35 & 2.50 & 0.07 & 64.1 & 126.8 \\
\hline 302.2 & 1.44 & 6.840 & 293.2 & 4.32 & 3.60 & 0.10 & 63.9 & 126.3 \\
\hline 306.2 & 1.24 & 4.349 & 296.2 & 4.35 & 4.91 & 0.13 & 63.6 & 125.4 \\
\hline 310.2 & 1.15 & 2.880 & 293.2 & 4.32 & 6.83 & 0.20 & 63.4 & 124.7 \\
\hline 314.2 & 0.71 & 1.303 & 293.2 & 2.06 & 9.34 & 0.26 & 63.2 & 124.0 \\
\hline 314.2 & 1.12 & 2.025 & 293.2 & 4.05 & 9.38 & 0.26 & 63.2 & 124.1 \\
\hline 318.2 & 1.40 & 1.872 & 293.2 & 4.32 & 12.74 & 0.34 & 63.0 & 123.4 \\
\hline 322.2 & 0.67 & 0.686 & 293.2 & 2.06 & 16.55 & 0.44 & 62.8 & 122.4 \\
\hline 326.2 & 1.28 & 0.960 & 293.2 & 2.88 & 22.66 & 0.59 & 62.5 & 122.0 \\
\hline 330.2 & 1.12 & 0.640 & 293.2 & 2.02 & 29.81 & 0.77 & 62.3 & 121.3 \\
\hline 334.2 & 1.29 & 0.576 & 293.2 & 1.19 & 38.06 & 0.98 & 62.1 & 120.4 \\
\hline 338.2 & 1.37 & 0.457 & 293.2 & 1.19 & 51.05 & 1.30 & 61.9 & 120.0 \\
\hline 340.2 & 1.26 & 0.377 & 296.2 & 1.19 & 57.56 & 1.46 & 61.8 & 119.6 \\
\hline 342.2 & 1.56 & 0.397 & 293.2 & 1.19 & 66.81 & 1.70 & 61.7 & 119.4 \\
\hline 344.2 & 1.58 & 0.358 & 296.2 & 1.19 & 76.00 & 1.92 & 61.6 & 119.1 \\
\hline 346.2 & 1.48 & 0.298 & 293.2 & 1.19 & 84.37 & 2.13 & 61.4 & 118.6 \\
\hline
\end{tabular}

${ }^{\text {a }}$ Saturation temperature measured with the standard uncertainty $(u(T)=0.1 \mathrm{~K}) .{ }^{\mathrm{b}}$ Mass of transferred sample condensed at $T=243 \mathrm{~K}$.

${ }^{c}$ Volume of nitrogen $\left(u(V)=0.005 \mathrm{dm}^{3}\right)$ used to transfer $m(u(m)=0.0001 \mathrm{~g})$ of the sample. Uncertainties are given as standard uncertainties.

${ }^{\mathrm{d}} T_{\mathrm{a}}$ is the temperature of the soap bubble meter used for measurement of the gas flow. ${ }^{\text {e }}$ Vapor pressure at temperature $T$, calculated from the $m$ and the residual vapor pressure at the condensation temperature calculated by an iteration procedure. ${ }^{\mathrm{f}}$ Standard uncertainties were calculated with $u\left(p_{i} / \mathrm{Pa}\right)=0.005+0.025\left(p_{i} / \mathrm{Pa}\right)$ for pressures below $5 \mathrm{~Pa}$ and with $u\left(p_{i} / \mathrm{Pa}\right)=0.025+0.025\left(p_{i} / \mathrm{Pa}\right)$ for pressures from 5 to $3000 \mathrm{~Pa}$. The standard uncertainties for $T, V, p, m$, are standard uncertainties with 0.683 confidence level. ${ }^{g}$ Calculated using the following equation: $\Delta_{1}^{\mathrm{g}} H_{m}^{o}(T)=-b+\Delta_{1}^{\mathrm{g}} C_{p, m}^{\mathrm{o}} \times T$. Uncertainty of the vaporization enthalpy $U\left(\Delta_{1}^{\mathrm{g}} H_{\mathrm{m}}^{\mathrm{o}}\right)$ is the expanded uncertainty (0.95 level of confidence) calculated according to procedure described elsewhere [7,8]. Uncertainties include uncertainties from the experimental conditions and the fitting equation, vapor pressures, and uncertainties from adjustment of vaporization enthalpies to the reference temperature $T=298.15 \mathrm{~K} .{ }^{h}$ Calculated using the following equation: $\Delta_{1}^{\mathrm{g}} S_{m}^{\mathrm{o}}(T)=\Delta_{1}^{\mathrm{g}} H_{m}^{\mathrm{o}} / T+R \times \ln \left(p_{\mathrm{i}} / p^{\mathrm{o}}\right)$ with $p^{\mathrm{o}}=0.1 \mathrm{MPa}$.

Vapor pressures for 2-methyl-quinoline, 3-methyl-quinolines, and 4-methyl-quinoline available in the literature were collected and compared in Figures S1-S3 in the Supplementary Materials. It was found that most of the literature data are reported at high 
temperatures that are close to the normal boiling temperatures of quinolines. Vapor pressures for the 3-methyl-quinoline and 4-methyl-quinoline were measured in this work using the transpiration method in a significantly lower temperature range (so-called ambient temperatures) and a direct comparison with earlier results is hardly possible. A generally good agreement of numerous vapor pressure sets reported for 2-methyl-quinoline can be seen in Figure S1. It has turned out, however, that for 3-methyl-quinoline (see Figure S2) and 4-methyl-quinoline (see Figure S3) the available vapor pressures are scarce. In our recent work $[9,10]$ we suggested that additional information from an internet source SciFinder [11] can be included for such conspicuous cases. In fact, SciFinder [11] compiles experimental boiling temperatures at different pressures. The reliability and accuracy of this data is questionable as it comes from the distillation of a synthesized material and not from special physicochemical studies. For alkyl-biphenyls [9] and amino-alcohols [10], however, we have shown that in most cases the numerous data on boiling temperatures, both at normal pressure and at reduced pressure, provide at least a reliable level of experimental vapor pressures and a reliable trend for the pressure-temperature dependence. Indeed, for 3-methyl-quinoline, the boiling points at different pressures compiled by SciFinder are in a reasonable trend (see Figure S2) between our low-temperature transpiration results and the high-temperature data set from the reference [12]. In Figure S3 the boiling points taken from SciFinder for 4-methyl-quinoline agree with the available vapor pressures at high temperatures $[12,13]$ and show the comparable trend with our low-temperature transpiration results.

\subsection{Vaporization Thermodynamics of Alkyl-Quinolines and Alkyl-Pyridines}

The experimental absolute vapor pressures can be conveniently fitted to the following Equation [3,4]:

$$
\mathrm{R} \times \ln \left(p_{i} / p_{r e f}\right)=\mathrm{a}+\frac{\mathrm{b}}{T}+\Delta_{1}^{\mathrm{g}} C_{\mathrm{p}, \mathrm{m}}^{\mathrm{o}} \times \ln \left(\frac{T}{T_{0}}\right)
$$

where $\mathrm{R}=8.31446 \mathrm{~J} \cdot \mathrm{K}^{-1} \cdot \mathrm{mol}^{-1}$ is the molar gas constant, the reference pressure, $p_{\text {ref }}=1 \mathrm{~Pa}$, and $\mathrm{a}$ and $\mathrm{b}$ are adjustable parameters; the arbitrary temperature $T_{0}$ applied in Equation (1) was chosen to be $T_{0}=298.15 \mathrm{~K}$ and $\Delta_{1}^{\mathrm{g}} \mathrm{C}_{\mathrm{p}, \mathrm{m}}^{\mathrm{o}}$ is the difference of the molar heat capacities of the gas and the liquid phases, respectively. The details on evaluation of the $\Delta_{1}^{\mathrm{g}} \mathrm{C}_{\mathrm{p}, \mathrm{m}}^{\mathrm{o}}$-values are given in Tables S2 and S3.

The results from the transpiration method have been treated by using Equation (4) in order to derive enthalpies of vaporization at the reference temperature $T=298.15 \mathrm{~K}$ according to Equation (2) (see more details in supporting information):

$$
\Delta_{1}^{\mathrm{g}} H_{\mathrm{m}}^{\mathrm{o}}(298.15 \mathrm{~K})=-b+\Delta_{1}^{\mathrm{g}} C_{p, \mathrm{~m}}^{\mathrm{o}} \times 298.15
$$

Approximation coefficients $a$ and $b$ of Equation (1) are given in Table 1. The combined uncertainties of the vaporization enthalpies include uncertainties from the experimental conditions of transpiration. Uncertainties in vapor pressure and uncertainties due to the temperature adjustment to $T=298.15 \mathrm{~K}$ are as described elsewhere $[7,8]$. The original absolute vapor pressures available in the literature for alkyl-quinolines and alkyl-pyridines were also treated by using Equations (1) and (2) in order to obtain vaporization enthalpies $\Delta_{1}^{\mathrm{g}} H_{\mathrm{m}}^{\mathrm{o}}(298.15 \mathrm{~K})$. A reasonable agreement of the vapor pressures data from SciFinder [11] with the results of thermochemical studies has prompted in collecting the boiling points at different pressures for alkyl-substituted pyridines and quinolines (see Table S4), where experimental vapor pressure studies were not performed. Uncertainties of the literature results have been also re-assessed in the same way as for our own experimental results. The compilation of the enthalpies of vaporization of the alkyl-quinolines is given in Table 2 . The compilation of the enthalpies of vaporization of the alkyl-pyridines is given in Table 3. 
Table 2. Compilation of enthalpies of vaporization, $\Delta_{1}^{\mathrm{g}} H_{\mathrm{m}}^{\mathrm{o}}$, for the quinoline derivatives.

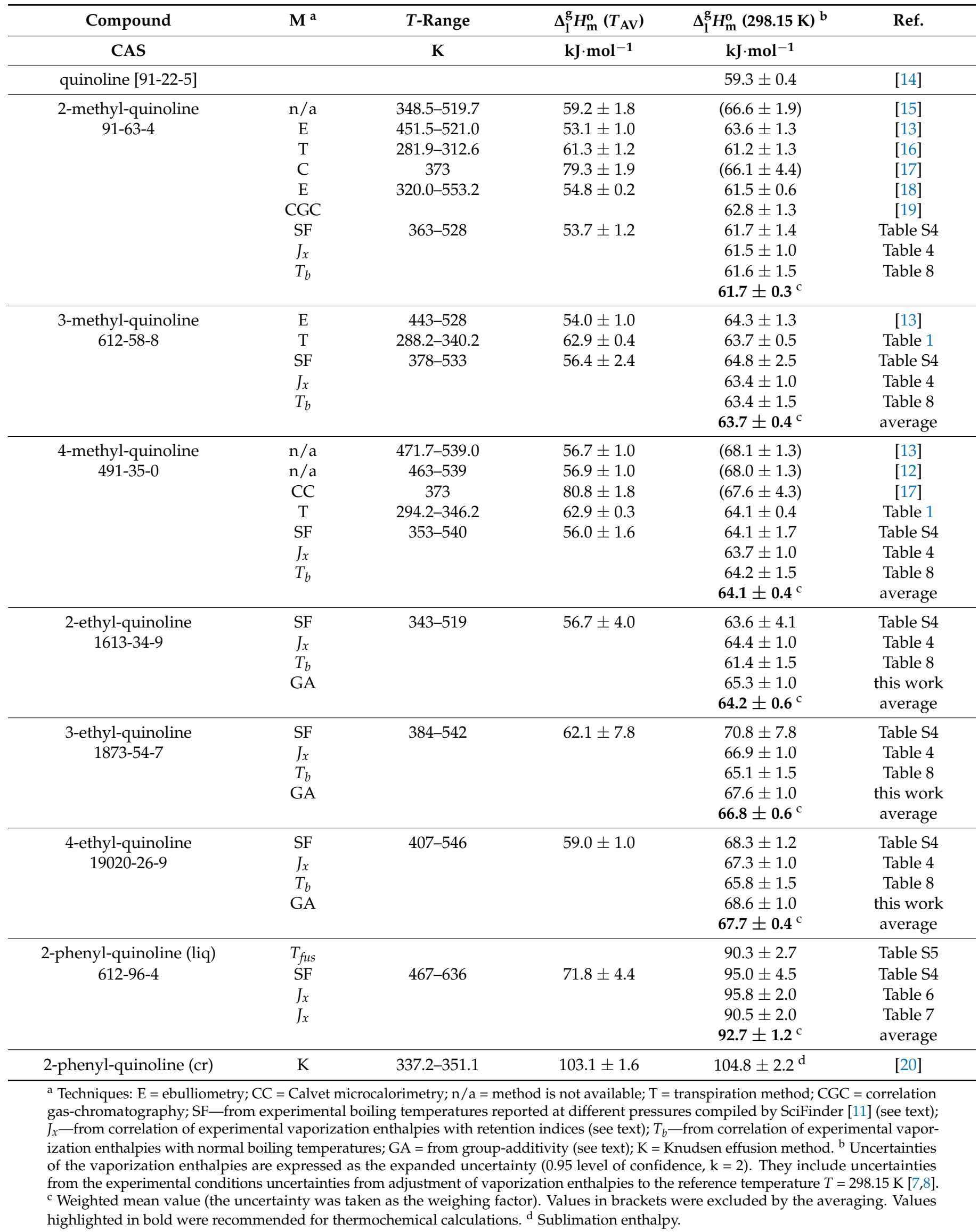


Table 3. Compilation of enthalpies of vaporization, $\Delta_{1}^{\mathrm{g}} H_{\mathrm{m}}^{\mathrm{o}}$, for the pyridine derivatives.

\begin{tabular}{|c|c|c|c|c|c|}
\hline Compound & $\mathbf{M}^{\mathbf{a}}$ & $T$-Range & $\Delta_{1}^{\mathrm{g}} H_{\mathrm{m}}^{\mathrm{o}}\left(T_{\mathrm{AV}}\right)$ & $\Delta_{1}^{\mathrm{g}} H_{\mathrm{m}}^{\mathrm{o}}(298.15 \mathrm{~K})^{\mathrm{b}}$ & Ref. \\
\hline CAS & & K & $\mathrm{kJ} \cdot \mathrm{mol}^{-1}$ & $\mathrm{~kJ} \cdot \mathrm{mol}^{-1}$ & \\
\hline pyridine [110-86-1] & & & & $40.2 \pm 0.2$ & [21] \\
\hline 2-methyl-pyridine [109-06-8] & & & & $42.5 \pm 0.2$ & [21] \\
\hline 3-methyl-pyridine [108-99-6] & & & & $44.6 \pm 0.2$ & [21] \\
\hline 4-methyl-pyridine [108-89-4] & & & & $44.8 \pm 0.2$ & [21] \\
\hline 2-ethyl-pyridine & $\mathrm{E}$ & $323-373$ & $42.9 \pm 0.2$ & $45.9 \pm 0.4$ & [22] \\
\hline \multirow[t]{5}{*}{$100-71-0$} & $\mathrm{CC}$ & 363 & $54.1 \pm 1.0$ & $44.7 \pm 1.0$ & [23] \\
\hline & $\mathrm{SF}$ & $312-422$ & $40.7 \pm 1.7$ & $44.6 \pm 1.8$ & Table S4 \\
\hline & $J_{x}$ & & & $46.2 \pm 1.0$ & Table 5 \\
\hline & $T_{b}$ & & & $46.0 \pm 1.5$ & Table 8 \\
\hline & & & & $45.9 \pm 0.4^{c}$ & average \\
\hline 3-ethyl-pyridine & $\mathrm{E}$ & $334-373$ & $44.3 \pm 0.4$ & $47.6 \pm 0.6$ & [22] \\
\hline \multirow[t]{4}{*}{ 536-78-7 } & SF & $349-438$ & $43.2 \pm 1.4$ & $49.0 \pm 1.5$ & Table S4 \\
\hline & $J_{x}$ & & & $48.5 \pm 1.0$ & Table 5 \\
\hline & $T_{b}$ & & & $48.6 \pm 1.5$ & Table 8 \\
\hline & & & & $48.0 \pm 0.5^{c}$ & average \\
\hline 4-ethyl-pyridine & $\mathrm{E}$ & $334-372$ & $45.1 \pm 0.4$ & $48.4 \pm 0.6$ & [22] \\
\hline \multirow[t]{6}{*}{$536-75-4$} & $\mathrm{n} / \mathrm{a}$ & $333-442$ & $42.9 \pm 1.5$ & $48.3 \pm 1.6$ & [12] \\
\hline & $\mathrm{T}$ & $284.5-352.8$ & $47.4 \pm 0.6$ & $48.5 \pm 0.7$ & {$[24]$} \\
\hline & $\mathrm{C}$ & 363 & $55.7 \pm 2.2$ & $46.3 \pm 2.9$ & {$[23]$} \\
\hline & $J_{x}$ & & & $49.6 \pm 1.0$ & Table 5 \\
\hline & $T_{b}$ & & & $49.3 \pm 1.5$ & Table 8 \\
\hline & & & & $48.6 \pm 0.4^{\mathrm{c}}$ & average \\
\hline 2-methyl-5-ethyl-pyridine & E & $325.1-449.8$ & $46.5 \pm 1.0$ & $52.5 \pm 1.1$ & [25] \\
\hline \multirow[t]{6}{*}{$104-90-5$} & $\mathrm{~T}$ & $252.8-275.9$ & $51.4 \pm 1.4$ & $49.0 \pm 1.5$ & [16] \\
\hline & $\mathrm{n} / \mathrm{a}$ & $348-451$ & $44.7 \pm 1.0$ & $51.5 \pm 1.1$ & [12] \\
\hline & $\mathrm{n} / \mathrm{a}$ & & & $(46.3 \pm 0.4)$ & [26] \\
\hline & $\mathrm{SF}$ & $332-451$ & $45.6 \pm 1.0$ & $51.8 \pm 1.1$ & Table S4 \\
\hline & $J_{x}$ & & & $52.0 \pm 1.0$ & Table 5 \\
\hline & & & & $51.5 \pm 0.6^{c}$ & average \\
\hline 2-n-propyl-pyridine & E & $339.1-372.8$ & $46.3 \pm 0.4$ & $50.2 \pm 0.6$ & [22] \\
\hline \multirow[t]{5}{*}{$622-39-9$} & $\mathrm{n} / \mathrm{a}$ & $338-445$ & $43.1 \pm 1.0$ & $49.5 \pm 1.1$ & [12] \\
\hline & SF & $324-446$ & $44.4 \pm 1.2$ & $50.0 \pm 1.3$ & Table S4 \\
\hline & $J_{x}$ & & & $51.2 \pm 1.0$ & Table 5 \\
\hline & $T_{b}$ & & & $49.7 \pm 1.5$ & Table 8 \\
\hline & & & & $50.2 \pm 0.4^{c}$ & average \\
\hline 3-n-propyl-pyridine & E & $350.2-371.7$ & $49.6 \pm 0.4$ & $53.9 \pm 0.7$ & [22] \\
\hline \multirow[t]{5}{*}{$4673-31-8$} & $\mathrm{n} / \mathrm{a}$ & $350-450$ & $43.1 \pm 1.0$ & $(58.5 \pm 1.1)$ & [12] \\
\hline & $\mathrm{SF}$ & $348-459$ & $46.8 \pm 1.0$ & $53.8 \pm 1.1$ & Table S4 \\
\hline & $J_{x}$ & & & $52.4 \pm 1.0$ & Table 5 \\
\hline & $T_{b}$ & & & $51.8 \pm 1.5$ & Table 8 \\
\hline & & & & $53.3 \pm 0.5^{c}$ & average \\
\hline 4-n-propyl-pyridine & E & $354.6-374.4$ & $48.4 \pm 1.2$ & $53.0 \pm 1.4$ & [22] \\
\hline \multirow[t]{6}{*}{$4673-31-8$} & $\mathrm{n} / \mathrm{a}$ & $354-465$ & $44.2 \pm 1.0$ & $51.8 \pm 1.2$ & [12] \\
\hline & $\mathrm{T}$ & 294.1-374.1 & $50.5 \pm 0.2$ & $52.7 \pm 0.3$ & [24] \\
\hline & SF & $352-464$ & $45.8 \pm 1.0$ & $52.9 \pm 1.2$ & Table S4 \\
\hline & $J_{x}$ & & & $53.4 \pm 1.0$ & Table 5 \\
\hline & $T_{b}$ & & & $52.6 \pm 1.5$ & Table 8 \\
\hline & & & & $52.7 \pm 0.3^{\mathrm{c}}$ & average \\
\hline
\end{tabular}


Table 3. Cont.

\begin{tabular}{|c|c|c|c|c|c|}
\hline Compound & $\mathbf{M}^{\mathbf{a}}$ & $T$-Range & $\Delta_{1}^{\mathrm{g}} H_{\mathrm{m}}^{\mathrm{o}}\left(T_{\mathrm{AV}}\right)$ & $\Delta_{1}^{\mathrm{g}} H_{\mathrm{m}}^{\mathrm{o}}(298.15 \mathrm{~K})^{\mathrm{b}}$ & Ref. \\
\hline CAS & & K & $\mathrm{kJ} \cdot \mathrm{mol}^{-1}$ & $\mathrm{~kJ} \cdot \mathrm{mol}^{-1}$ & \\
\hline $\begin{array}{c}\text { 2-n-butyl-pyridine } \\
\text { 5058-19-5 }\end{array}$ & $\begin{array}{l}\mathrm{SF} \\
J_{x} \\
T_{b}\end{array}$ & $340-465$ & $46.8 \pm 1.6$ & $\begin{array}{r}54.3 \pm 1.7 \\
54.7 \pm 1.0 \\
52.8 \pm 1.5 \\
\mathbf{5 4 . 2} \pm \mathbf{0 . 8}^{\mathrm{c}}\end{array}$ & $\begin{array}{c}\text { Table S4 } \\
\text { Table } 5 \\
\text { Table } 8 \\
\text { average }\end{array}$ \\
\hline $\begin{array}{c}\text { 3-n-butyl-pyridine } \\
539-32-2\end{array}$ & $\begin{array}{l}\mathrm{SF} \\
J_{x} \\
T_{b}\end{array}$ & $347-482$ & $49.8 \pm 2.0$ & $\begin{array}{c}58.2 \pm 2.1 \\
56.1 \pm 1.0 \\
55.3 \pm 1.5 \\
\mathbf{5 6 . 2} \pm \mathbf{0 . 8}^{\mathrm{c}}\end{array}$ & $\begin{array}{c}\text { Table S4 } \\
\text { Table } 5 \\
\text { Table } 8 \\
\text { average }\end{array}$ \\
\hline $\begin{array}{c}\text { 4-n-butyl-pyridine } \\
\text { 5335-75-1 }\end{array}$ & $\begin{array}{l}\mathrm{SF} \\
J_{x} \\
T_{b}\end{array}$ & $371-482$ & $48.9 \pm 2.0$ & $\begin{array}{c}58.3 \pm 2.1 \\
55.4 \pm 1.0 \\
55.5 \pm 1.5 \\
\mathbf{5 5 . 8} \pm \mathbf{0 . 8}^{\mathrm{c}}\end{array}$ & $\begin{array}{c}\text { Table S4 } \\
\text { Table } 5 \\
\text { Table } 8 \\
\text { average }\end{array}$ \\
\hline
\end{tabular}

a Techniques: $\mathrm{E}$ = ebulliometry; $\mathrm{CC}=$ Calvet microcalorimetry; $\mathrm{n} / \mathrm{a}=$ method is not available; $T$ = transpiration method; SF-from experimental boiling temperatures reported at different pressures compiled by SciFinder [11] (see text); $J_{x}$-from correlation of experimental vaporization enthalpies with retention indices (see text); $T_{b}$-from correlation of experimental vaporization enthalpies with normal boiling temperatures. ${ }^{b}$ Uncertainties of the vaporization enthalpies are expressed as the expended uncertainty $(0.95$ level of confidence, $\mathrm{k}=2)$. They include uncertainties from the experimental conditions uncertainties from adjustment of vaporization enthalpies to the reference temperature $T=298.15 \mathrm{~K}[7,8] .{ }^{\mathrm{c}}$ Weighted mean value (the uncertainty was taken as the weighing factor). Values in brackets were excluded by the averaging. Values highlighted in bold were recommended for thermochemical calculations.

A quick look at columns 5 in Tables 2 and 3 shows a remarkable consistency of the $\Delta_{1}^{\mathrm{g}} H_{\mathrm{m}}^{\mathrm{o}}(298.15 \mathrm{~K})$-values for most of the alkyl-substituted quinolines and pyridines listed in the tables. It should be noted, however, that such a systematic treatment of the available vapor pressures of quinolines and pyridines towards vaporization enthalpies was carried out for the first time. As a rule, only the vapor pressure-temperature dependencies are reported in the literature, and only a few papers [14,18] deal with the evaluation of $\Delta_{1}^{\mathrm{g}} H_{\mathrm{m}}^{\mathrm{o}}$ $(298.15 \mathrm{~K})$-values. The reason for that is apparent from columns 3 and 4 of Tables 2 and 3. In fact, the average temperatures, $T_{\mathrm{av}}$, from vapor pressure studies found in the literature, e.g., for 2-methyl- and 3-methyl-quinoline, are around 480-500 K. Therefore, the adjustment of the vaporization enthalpy over $180-200 \mathrm{~K}$ to $T=298.15 \mathrm{~K}$, taking into account the ambiguities in the evaluation of the $\Delta_{1}^{\mathrm{g}} C_{p, \mathrm{~m}}^{\mathrm{o}}$-values, could significantly influence the results. With this preface, the very good agreement of the $\Delta_{1}^{\mathrm{g}} H_{\mathrm{m}}^{\mathrm{o}}(298.15 \mathrm{~K})$-values derived from the "high-temperature" methods (ebulliometry, calorimetry, etc.) and "low-temperature" methods (e.g., transpiration) can be considered as evidence of the reliability of the $\Delta_{1}^{\mathrm{g}} \mathrm{C}_{p, \mathrm{~m}^{\mathrm{o}}}{ }^{-}$ values evaluated in Table S2 for the temperature adjustment. There were only a few inconsistent sets among the data collected in Tables 2 and 3, and not always were we able to find a reasonable explanation for each of these outliers. For 4-methyl-quinolines and alkylpyridines we involved vapor pressures data reported in the comprehensive compilation by Stephenson and Malanowski [12]. The only Antoine equation coefficients are given in this source, without attestation of sample purity or the method used. For this reason, the agreement or disagreement with data taken from this compilation is to be considered as questionable. The same explanation applies to data for 2-methylquinoline from the Stull compilation published in 1947 [15]. At the same time, we have no reasonable explanation for the deviation of the Ribeiro da Silva's calorimetric results [17] for 2-methylquinoline and 4-methylquinoline. To increase reliability and accuracy, for most of the alkyl-quinolines and alkyl-pyridines evaluated in Tables 2 and 3, the weighted mean values $\Delta_{1}^{\mathrm{g}} H_{\mathrm{m}}^{\mathrm{o}}(298.15 \mathrm{~K})$ were calculated (uncertainties were used as the weighing factor) and they have been recommended for further thermochemical calculations. 


\subsection{Validation of Vaporization Enthalpies, $\Delta_{l}^{g} H_{m}^{o}(298.15 \mathrm{~K})$, of Alkyl-Quinolines and Alkyl-Pyridines}

As can be seen from Tables 2 and 3, the vaporization enthalpies, $\Delta_{1}^{\mathrm{g}} H_{\mathrm{m}}^{\mathrm{o}}(298.15 \mathrm{~K})$, derived from vapor pressures measured by the conventional methods, as well as those derived from the SciFinder [11] data, are in good agreement for all alkyl-quinolines and alkyl-pyridines compiled in these tables. This good agreement has increased the usefulness of extracting experimental boiling temperatures at various pressures compiled by SciFinder [11] for evaluating the scarce thermodynamic data. Nevertheless, taking into account the less accurate data from SciFinder, as well as the unexplainable outlying of the vaporization enthalpies derived for 2-methyl-quinoline and 4-methyl-quinoline directly by calorimetry [17], an additional validation of the $\Delta_{1}^{\mathrm{g}} H_{\mathrm{m}}^{\mathrm{o}}(298.15 \mathrm{~K})$-values evaluated in Tables 2 and 3 is required. This additional validation was conducted in this work using the available alkyl-quinolines and alkyl-pyridines chromatographic retention indices (Section 3.3.1), using correlation with the normal boiling temperatures (Section 3.3.2), using group-additivity principles (Section 3.3.3), and using the correlation with the chain length (Section 3.3.4).

\subsubsection{Validation Using Retention Indices $J_{x}$}

The additional validation of the $\Delta_{1}^{\mathrm{g}} H_{\mathrm{m}}^{\mathrm{o}}(298.15 \mathrm{~K})$-values evaluated in Tables 2 and 3 was carried out in this work using the available chromatographic retention indices for alkyl-quinolines and alkyl-pyridines [26-31]. We know that the $\Delta_{1}^{\mathrm{g}} H_{\mathrm{m}}^{\mathrm{o}}(298.15 \mathrm{~K})$-values and retention indices are usually linearly correlated in series of structurally similar compounds [32]. Indeed, we derived a high-quality linear correlation between vaporization enthalpies $\Delta_{1}^{\mathrm{g}} H_{\mathrm{m}}^{\mathrm{o}}(298.15 \mathrm{~K})$ and a set of Kovats's indices, $J_{x}$, of only alkyl-quinolines collected in Table 4:

$$
\Delta_{\mathrm{l}}^{\mathrm{g}} H_{\mathrm{m}}^{\mathrm{o}}(298.15 \mathrm{~K}) /\left(\mathrm{kJ} \cdot \mathrm{mol}^{-1}\right)=9.2+0.0406 \times J_{x} \text { with }\left(R^{2}=0.9947\right)
$$

In addition, a high-quality linear correlation between vaporization enthalpies $\Delta_{1}^{\mathrm{g}} H_{\mathrm{m}}^{\mathrm{o}}$ $(298.15 \mathrm{~K})$ and a combined set of Kovats's indices, $J_{x}$, of alkyl-pyridines and alkyl-quinolines collected in Table 5 was derived:

$$
\Delta_{1}^{\mathrm{g}} H_{\mathrm{m}}^{\mathrm{o}}(298.15 \mathrm{~K}) /\left(\mathrm{kJ} \cdot \mathrm{mol}^{-1}\right)=15.3+0.0357 \times J_{x} \text { with }\left(R^{2}=0.9970\right)
$$

We deliberately performed the $\Delta_{1}^{\mathrm{g}} H_{\mathrm{m}}^{\mathrm{o}}(298.15 \mathrm{~K})$ correlations with two significantly different sets of the retention indices.

\begin{tabular}{|c|c|c|c|c|}
\hline & $J_{x}{ }^{\mathrm{a}}$ & $\Delta_{1}^{\mathrm{g}} H_{\mathrm{m}}^{\mathrm{o}}(298.15 \mathrm{~K})_{\exp }$ & $\Delta_{1}^{\mathrm{g}} H_{\mathrm{m}}^{\mathrm{o}}(298.15 \mathrm{~K})_{\text {calc }}{ }^{\mathrm{b}}$ & $\Delta^{\mathrm{c}}$ \\
\hline Compound & & $\mathrm{kJ} \cdot \mathrm{mol}^{-1}$ & $\mathrm{~kJ} \cdot \mathrm{mol}^{-1}$ & $\mathrm{~kJ} \cdot \mathrm{mol}^{-1}$ \\
\hline quinoline & 1231 & $59.3 \pm 0.2[14]$ & 59.2 & 0.1 \\
\hline 2-methyl-quinoline & 1294 & & 61.7 & \\
\hline 8-methyl-quinoline & 1304 & $61.9 \pm 0.7[18]$ & 62.1 & -0.2 \\
\hline 7-methyl-quinoline & 1338 & & 63.5 & \\
\hline 6-methyl-quinoline & 1343 & $63.9 \pm 0.3[33]$ & 63.7 & 0.2 \\
\hline 3-methyl-quinoline & 1346 & $63.7 \pm 0.4$ [Table 2] & 63.8 & -0.1 \\
\hline 5-methyl-quinoline & 1355 & & 64.2 & \\
\hline 4-methyl-quinoline & 1357 & & 64.3 & \\
\hline 2,8-dimethyl-quinoline & 1361 & & 64.5 & \\
\hline 2,6-dimethyl-quinoline & 1397 & $66.0 \pm 0.7[34]$ & 65.9 & 0.1 \\
\hline 2,7-dimethyl-quinoline & 1400 & & 66.0 & \\
\hline 6,8-dimethyl-quinoline & 1408 & & 66.4 & \\
\hline 2,4-dimethyl-quinoline & 1417 & & 66.7 & \\
\hline 5,8-dimethyl-quinoline & 1427 & & 67.1 & \\
\hline 2,3-dimethyl-quinoline & 1427 & & 67.1 & \\
\hline
\end{tabular}

Table 4. Correlation of vaporization enthalpies, $\Delta_{l}^{g} H_{m}^{o}(298.15 \mathrm{~K})$, of quinolines with their Kovats's indices $\left(J_{x}\right)$.

${ }^{\mathrm{a}}$ Kovats's indices at $413 \mathrm{~K}, J_{x}$, on the standard non-polar column OV-101 [27]. ${ }^{\mathrm{b}}$ Calculated using Equation (3) with the assessed expanded uncertainty of $\pm 1.0 \mathrm{~kJ} \cdot \mathrm{mol}^{-1}(0.95$ level of confidence, $\mathrm{k}=2) .{ }^{\mathrm{c}}$ Difference between column 3 and 4 in this table. 
As can be seen from Tables 4 and 5 the "theoretical" vaporization enthalpies calculated with Equations (3) and (4) are very close. In addition, the differences between experimental vaporization enthalpies and values calculated according to Equations (3) and (4) are mostly below $1 \mathrm{~kJ} \cdot \mathrm{mol}^{-1}$. Hence, the uncertainties of enthalpies of vaporization which are estimated from the correlation of $\Delta_{1}^{\mathrm{g}} H_{\mathrm{m}}^{\mathrm{o}}(298.15 \mathrm{~K})$ with Kovats's indices are evaluated with an uncertainty of $\pm 1.0 \mathrm{~kJ} \cdot \mathrm{mol}^{-1}$.

The "theoretical" results derived from these correlations are given in Tables 2 and 3 and labeled as $J_{x}$. These results are valuable to support the level of enthalpy of vaporization derived from other methods, especially in cases where data are scarce (e.g., for the most of ethyl, propyl and butyl-substituted pyridines and quinolines). From these tables it can be seen that for every compound agreement among $\Delta_{1}^{\mathrm{g}} H_{\mathrm{m}}^{\mathrm{o}}(298.15 \mathrm{~K}$-values, which were derived in different ways, all lie within the assigned error bars. To get more confidence and reliability, we calculated the weighted average (the uncertainty was used as a weighing factor) for alkyl-quinolines and alkyl-pyridines given in Tables 2 and 3. These values are highlighted in bold and are recommended for thermochemical calculations.

Table 5. Correlation of vaporization enthalpies $\Delta_{l}^{g} H_{m}^{o}(298.15 \mathrm{~K})$ of substituted pyridines and quinolines with their Kovats's there is no copyright issue indices on non-polar columns.

\begin{tabular}{|c|c|c|c|c|}
\hline & $J_{x}$ & $\Delta_{1}^{\mathrm{g}} H_{\mathrm{m} \exp }^{\mathrm{o}}[21]^{\mathrm{a}}$ & $\Delta_{1}^{\mathrm{g}} H_{\mathrm{m}}^{\mathrm{o}}(298.15 \mathrm{~K})_{\text {calc }}{ }^{\mathrm{b}}$ & $\Delta^{\mathrm{c}}$ \\
\hline Compound & & $\mathrm{kJ} \cdot \mathrm{mol}^{-1}$ & $\mathrm{~kJ} \cdot \mathrm{mol}^{-1}$ & $\mathrm{~kJ} \cdot \mathrm{mol}^{-1}$ \\
\hline pyridine & $695[28]$ & $40.2 \pm 0.2$ & 40.1 & 0.1 \\
\hline 2-methyl-pyridine & $742[28]$ & $42.5 \pm 0.2$ & 41.8 & 0.7 \\
\hline 3-methyl-pyridine & $831[28]$ & $44.6 \pm 0.2$ & 45.0 & -0.4 \\
\hline 4-methyl-pyridine & $833[28]$ & $44.8 \pm 0.2$ & 45.0 & -0.2 \\
\hline 2,6-dimethyl-pyridine & $829[28]$ & $45.4 \pm 0.2$ & 44.9 & 0.5 \\
\hline 2,4-dimethyl-pyridine & $904[28]$ & $47.5 \pm 0.2$ & 47.6 & -0.1 \\
\hline 2,5-dimethyl-pyridine & $894[28]$ & $47.8 \pm 0.2$ & 47.2 & 0.6 \\
\hline 3,5-dimethyl-pyridine & $980[28]$ & $49.5 \pm 0.2$ & 50.3 & -0.8 \\
\hline 2,3-dimethyl-pyridine & $901[28]$ & $47.7 \pm 0.2$ & 47.5 & 0.2 \\
\hline 3,4-dimethyl-pyridine & $992[28]$ & $50.5 \pm 0.2$ & 50.7 & -0.2 \\
\hline 2-methyl-5-ethyl-pyridine & $1029[29]$ & $51.5 \pm 0.6[$ Table 3$]$ & 52.0 & -0.5 \\
\hline 2-ethyl-pyridine & $866[30]$ & & 46.2 & \\
\hline 3-ethyl-pyridine & $930[30]$ & & 48.5 & \\
\hline 4-ethyl-pyridine & $962[30]$ & & 49.6 & \\
\hline 2-n-propyl-pyridine & $1005[30]$ & & 51.2 & \\
\hline 3-n-propyl-pyridine & $1038[30]$ & & 52.4 & \\
\hline 4-n-propyl-pyridine & $1067[30]$ & & 53.4 & \\
\hline 2-n-butyl-pyridine & $1105[31]$ & & 54.7 & \\
\hline 3-n-butyl-pyridine & $1142[31]$ & & 56.1 & \\
\hline 4-n-butyl-pyridine & $1124[31]$ & & 55.4 & \\
\hline quinoline & $1231[27]$ & $59.3 \pm 0.2[14]$ & 59.2 & 0.1 \\
\hline 2-methyl-quinoline & $1294[27]$ & $61.6 \pm 0.6[18]$ & 61.5 & 0.1 \\
\hline 3-methyl-quinoline & $1346[27]$ & $63.7 \pm 0.5[$ Table 1$]$ & 63.4 & 0.3 \\
\hline 4-methyl-quinoline & $1357[27]$ & $64.1 \pm 0.4$ [Table 1$]$ & 63.7 & 0.4 \\
\hline 2-ethyl-quinoline & $1374[27]$ & & 64.4 & \\
\hline 3-ethyl-quinoline & $1446[27]$ & & 66.9 & \\
\hline 4-ethyl-quinoline & $1457[27]$ & & 67.3 & \\
\hline
\end{tabular}

${ }^{a}$ Uncertainties are expressed as the twice standard deviation. ${ }^{b}$ Calculated using Equation (4). ${ }^{c}$ Difference between column 3 and 4 in this table.

Such good consistency of results obtained from the $\Delta_{1}^{\mathrm{g}} H_{\mathrm{m}}^{\mathrm{o}}(298.15 \mathrm{~K})-J_{\mathrm{x}}$ correlations can be seen as additional validation of the data evaluated in Tables 2 and 3. Moreover, the retention indices for dimethyl-quinolines also available on the OV-101 column [27] have been utilized according to Equation (3) to estimate the vaporization enthalpies for the series of different dimethyl-quinolines (see Table 4).

The 2-phenyl-quinoline is of particular interest for hydrogen storage. It is obvious that according to the reaction R3 (Figure 1) this molecule releases 8 moles of hydrogen. However, only the sublimation enthalpy, $\Delta_{\mathrm{cr}}^{\mathrm{g}} H_{\mathrm{m}}^{\mathrm{o}}(298.15 \mathrm{~K})$, for this compound is avail- 
able [20] (see Table 2), but the enthalpy of vaporization is lacking in the literature. The required vaporization enthalpy of $\Delta_{1}^{\mathrm{g}} H_{\mathrm{m}}^{\mathrm{o}}(298.15 \mathrm{~K})=90.3 \pm 2.7 \mathrm{~kJ} \cdot \mathrm{mol}^{-1}$, was derived from the sublimation and fusion enthalpy as it shown in Table S5. This single value must also be further validated. The few boiling points at the reduced pressures were found for 2-phenyl-quinoline in the SciFinder [11] (see Table S4). The level of the value $\Delta_{1}^{\mathrm{g}} H_{\mathrm{m}}^{\mathrm{o}}(298.15 \mathrm{~K})=95.0 \pm 4.5 \mathrm{~kJ} \cdot \mathrm{mol}^{-1}$ derived from this data is generally the same as the previous one, even if it is not exact. To ascertain the $\Delta_{1}^{\mathrm{g}} H_{\mathrm{m}}^{\mathrm{o}}(298.15 \mathrm{~K})$ estimate, we searched for the Kovats's index for 2-phenyl-quinoline, but none were found. Instead, we found the chromatographic Lee retention indices, $J_{\text {Lee }}$, for 2-phenylquinoline and its parent compounds. Two independent data sets of Lee indices on the SE-52 column [35] (Table 6) and on the HP-5 column [36] (Table 7) were collected for correlation with vaporization enthalpies.

Table 6. Correlation of vaporization enthalpies, $\Delta_{l}^{g} H_{m}^{o}(298.15 \mathrm{~K})$, of amino-aromatics with their Lee indices $\left(J_{L e e}\right)$ on SE-52 column $^{\mathrm{a}}$.

\begin{tabular}{|c|c|c|c|c|}
\hline & $J_{\text {Lee }} \mathbf{b}^{\mathbf{b}}$ & $\Delta_{1}^{\mathrm{g}} H_{\mathrm{m}}^{\mathrm{o}}(298 \mathrm{~K})_{\exp }$ & $\Delta_{1}^{\mathrm{g}} H_{\mathrm{m}}^{\mathrm{o}}(298 \mathrm{~K})_{\text {calc }^{c}}^{\mathrm{c}}$ & $\Delta^{\mathrm{d}}$ \\
\hline Compound & & $\mathrm{kJ} \cdot \mathrm{mol}^{-1}$ & $\mathrm{~kJ} \cdot \mathrm{mol}^{-1}$ & $\mathrm{~kJ} \cdot \mathrm{mol}^{-1}$ \\
\hline quinoline & 210.2 & $59.3 \pm 0.2[14]$ & 59.1 & 0.2 \\
\hline diphenylamine & 279.3 & $79.5 \pm 0.4[37]$ & 79.4 & 0.1 \\
\hline 1-amino-naphthalene & 261.6 & $73.3 \pm 0.4[38]$ & 74.2 & -0.9 \\
\hline 2-amino-naphthalene & 264.3 & $74.6 \pm 1.0[38]$ & 75.0 & -0.4 \\
\hline 2-phenyl-aniline & 273.1 & $78.4 \pm 0.1[39]$ & 77.6 & 0.8 \\
\hline 2-phenyl-quinoline & 335.1 & & $95.8 \pm 2.0$ & \\
\hline
\end{tabular}

${ }^{a}$ Uncertainties in this table are expressed as twice the standard deviation. ${ }^{\mathrm{b}}$ Lee indices, $J_{\text {Lee, }}$ on the standard non-polar column SE-52 [35].

c Calculated using equation: $\Delta_{l}^{g} H_{m}^{o}(298.15 \mathrm{~K}) /\left(\mathrm{kJ} \cdot \mathrm{mol}^{-1}\right)=-2.6+0.2935 \times J_{\text {Lee }}$ with $\left(R^{2}=0.9936\right)$ and with the assessed uncertainty of $\pm 2.0 \mathrm{~kJ} \cdot \mathrm{mol}^{-1}$. ${ }^{\mathrm{d}}$ Difference between column 3 and 4 in this table.

Table 7. Correlation of vaporization enthalpies, $\Delta_{l}^{g} H_{m}^{o}(298.15 \mathrm{~K})$, of aromatics and amino-aromatics with their Lee indices $\left(J_{\text {Lee }}\right)$ on HP-5 column ${ }^{\text {a }}$.

\begin{tabular}{|c|c|c|c|c|}
\hline & $J_{L e e} \mathbf{b}$ & $\Delta_{1}^{\mathrm{g}} H_{\mathrm{m}}^{\mathrm{o}}(298 \mathrm{~K}) \exp$ & $\Delta_{1}^{\mathrm{g}} H_{\mathrm{m}}^{\mathrm{o}}(298 \mathrm{~K})_{\text {calc }^{c}}{ }^{\mathrm{c}}$ & $\Delta^{\mathrm{d}}$ \\
\hline Compound & & $\mathrm{kJ} \cdot \mathrm{mol}^{-1}$ & $\mathrm{~kJ} \cdot \mathrm{mol}^{-1}$ & $\mathrm{~kJ} \cdot \mathrm{mol}^{-1}$ \\
\hline biphenyl & 235.7 & $65.8 \pm 0.2[40]$ & 64.6 & 1.2 \\
\hline 4-methyl-biphenyl & 255.6 & $69.2 \pm 0.4[9,41]$ & 69.6 & -0.4 \\
\hline 1-phenyl-naphthaline & 312.6 & $83.2 \pm 0.4[42]$ & 83.9 & -0.7 \\
\hline 2-phenyl-pyridine & 248.9 & $68.4 \pm 1.8^{\mathrm{e}}$ & 67.9 & 0.5 \\
\hline 3-phenyl-pyridine & 249.8 & $68.3 \pm 1.5^{\mathrm{e}}$ & 68.2 & 0.1 \\
\hline 4-phenyl-pyridine & 256.1 & $68.4 \pm 3.5[43]$ & 69.7 & -1.3 \\
\hline 9-phenyl-carbazole & 377.1 & $100.5 \pm 1.6[44]$ & 100.0 & 0.5 \\
\hline 2-phenyl-quinoline & 339.1 & & $90.5 \pm 2.0$ & \\
\hline
\end{tabular}

${ }^{a}$ Uncertainties in this table are expressed as twice the standard deviation. ${ }^{\mathrm{b}}$ Lee indices, $\mathrm{J}_{\text {Lee }}$, on the standard non-polar column HP-5 [36].

${ }^{c}$ Calculated using equation: $\Delta_{l}^{g} H_{m}^{o}(298.15 \mathrm{~K}) /\left(\mathrm{kJ} \cdot \mathrm{mol}^{-1}\right)=5.7+0.2500 \times J_{\text {Lee }}$ with $\left(R^{2}=0.9956\right)$ and with the assessed uncertainty of $\pm 2.0 \mathrm{~kJ} \cdot \mathrm{mol}^{-1}$. ${ }^{\mathrm{d}}$ Difference between column 3 and 4 in this table. ${ }^{\mathrm{e}}$ Weighted average from values reported in Refs. [43,45].

We derived high-quality linear correlations between vaporization enthalpies $\Delta_{1}^{\mathrm{g}} H_{\mathrm{m}}^{\mathrm{o}}$ $(298.15 \mathrm{~K})$ and the sets of Lee indices, $J_{\text {Lee }}$, for both types of chromatographic columns. These correlations are given in the footnotes for Tables 6 and 7 and were used to estimate the enthalpy of vaporization of 2-phenylquinoline independently for each column (see Table 2, column 5). All four $\Delta_{1}^{\mathrm{g}} H_{\mathrm{m}}^{\mathrm{o}}(298.15 \mathrm{~K}$ )-entries derived for 2-phenyl-quinoline from phase transition $\left(T_{f u s}\right)$, SciFinder $(\mathrm{SF})$, and retention indices $\left(J_{x}\right)$ are in fair agreement, taking into account the assigned experimental uncertainties. The weighted average, $\Delta_{1}^{\mathrm{g}} H_{\mathrm{m}}^{\mathrm{o}}(298.15 \mathrm{~K})=92.7 \pm 1.2 \mathrm{~kJ} \cdot \mathrm{mol}^{-1}$, was recommended for further thermochemical calculations. 


\subsubsection{Validation Using Normal Boiling Temperatures $T_{b}$}

The alkyl-substituted pyridines and quinolines are high-boiling but thermally stable compounds. The reliable values of their normal boiling temperatures, $T_{b}$, are readily available in the literature [11]. A possible correlation of the $\Delta_{1}^{\mathrm{g}} H_{\mathrm{m}}^{\mathrm{o}}(298.15 \mathrm{~K})$ and the $T_{b}$ values could help to establish consistency of both thermodynamic quantities. In Table 8 we collected the $T_{b}$ values for the same set of substituted pyridines and quinolines as for the $J_{x}$ correlations.

Table 8. Correlation of vaporization enthalpies $\Delta_{l}^{g} H_{m}^{o}(298.15 \mathrm{~K})$ of substituted pyridines and quinolines with their $T_{b}$ normal boiling temperatures ${ }^{a}$.

\begin{tabular}{|c|c|c|c|c|}
\hline & $T_{b}[11]$ & $\Delta_{1}^{\mathrm{g}} H_{\mathrm{m}}^{\mathrm{o}}(298.15 \mathrm{~K}) \exp$ & $\Delta_{1}^{\mathrm{g}} H_{\mathrm{m}}^{\mathrm{o}}(298.15 \mathrm{~K})_{\text {calc }}{ }^{\mathrm{b}}$ & $\Delta^{\mathrm{c}}$ \\
\hline Compound & $\mathbf{K}$ & $\mathrm{kJ} \cdot \mathrm{mol}^{-1}$ & $\mathrm{~kJ} \cdot \mathrm{mol}^{-1}$ & $\mathrm{~kJ} \cdot \mathrm{mol}^{-1}$ \\
\hline pyridine & 388.5 & $40.2 \pm 0.2$ & 40.5 & -0.3 \\
\hline 2-methyl-pyridine & 402.6 & $42.5 \pm 0.2$ & 42.8 & -0.3 \\
\hline 3-methyl-pyridine & 417.3 & $44.6 \pm 0.2$ & 45.1 & -0.5 \\
\hline 4-methyl-pyridine & 418.3 & $44.8 \pm 0.2$ & 45.3 & -0.5 \\
\hline 2,6-dimethyl-pyridine & 417.3 & $45.4 \pm 0.2$ & 45.1 & 0.3 \\
\hline 2,4-dimethyl-pyridine & 431.7 & $47.5 \pm 0.2$ & 47.4 & 0.1 \\
\hline 2,5-dimethyl-pyridine & 430.2 & $47.8 \pm 0.2$ & 47.2 & 0.6 \\
\hline 3,5-dimethyl-pyridine & 445.2 & $49.5 \pm 0.2$ & 49.6 & -0.1 \\
\hline 2,3-dimethyl-pyridine & 434.4 & $47.7 \pm 0.2$ & 47.9 & -0.2 \\
\hline 3,4-dimethyl-pyridine & 452.3 & $50.5 \pm 0.2$ & 50.7 & -0.2 \\
\hline 2-methyl-5-ethyl-pyridine & 451.5 & $51.5 \pm 0.6$ [Table 3] & 50.6 & 0.9 \\
\hline 2-ethyl-pyridine & 423.0 & & 46.0 & \\
\hline 3-ethyl-pyridine & 438.8 & & 48.6 & \\
\hline 4-ethyl-pyridine & 443.2 & & 49.3 & \\
\hline 2-n-propyl-pyridine & 446.0 & & 49.7 & \\
\hline 3-n-propyl-pyridine & 459.0 & & 51.8 & \\
\hline 4-n-propyl-pyridine & 464.0 & & 52.6 & \\
\hline 2-n-butyl-pyridine & 465.0 & & 52.8 & \\
\hline 3-n-butyl-pyridine & 481.0 & & 55.3 & \\
\hline 4-n-butyl-pyridine & 482.0 & & 55.5 & \\
\hline quinoline & 510.3 & $59.3 \pm 0.2[14]$ & 60.1 & -0.8 \\
\hline 2-methyl-quinoline & 519.7 & $61.7 \pm 0.3^{d}$ & 61.6 & 0.0 \\
\hline 3-methyl-quinoline & 532.8 & $63.7 \pm 0.4^{\mathrm{d}}$ & 63.7 & 0.0 \\
\hline 4-methyl-quinoline & 536.0 & $64.1 \pm 0.4^{\mathrm{d}}$ & 64.2 & -0.1 \\
\hline 2-ethyl-quinoline & 518.7 & & 61.4 & \\
\hline 3-ethyl-quinoline & 542.0 & & 65.1 & \\
\hline 4-ethyl-quinoline & 546.0 & & 65.8 & \\
\hline
\end{tabular}

${ }^{a}$ Uncertainties are expressed as the twice standard deviations. ${ }^{\mathrm{b}}$ Calculated using Equation (5). ${ }^{\mathrm{c}}$ Difference between experimental and calculated by Equation (5) values. ${ }^{\mathrm{d}}$ Recommended in Table 2 values.

In fact, linear correlation of $\Delta_{1}^{\mathrm{g}} H_{\mathrm{m}}^{\mathrm{o}}(298.15 \mathrm{~K})$-values with $T_{b}$ values were found for the structurally parent alkyl-substituted pyridines and quinolines. For the data set collected in Table 8, we derived the following correlation:

$$
\Delta_{1}^{\mathrm{g}} H_{\mathrm{m}}^{\mathrm{o}}(298.15 \mathrm{~K}) /\left(\mathrm{kJ} \cdot \mathrm{mol}^{-1}\right)=-22.0+0.1608 \times T_{b} \text { with }\left(R^{2}=0.997\right)
$$

In addition, in this case the results of the $\Delta_{1}^{\mathrm{g}} H_{\mathrm{m}}^{\mathrm{o}}(298.15 \mathrm{~K})$ correlations with boiling temperatures are in a good agreement with those of the other method (see Table 2, the values which are labeled as $T_{b}$ ). This good agreement can therefore be seen as an additional validation of the experimental data for the $\Delta_{1}^{\mathrm{g}} H_{\mathrm{m}}^{\mathrm{o}}(298.15 \mathrm{~K})$ evaluated in this work (see Tables 2 and 3). From Table 8 it can be seen that differences between experimental and according to Equation (5) values are well below $1 \mathrm{~kJ} \cdot \mathrm{mol}^{-1}$. Consequently, the uncertainties of the enthalpies of vaporization which are estimated from the $\Delta_{1}^{\mathrm{g}} H_{\mathrm{m}}^{\mathrm{o}}(298.15 \mathrm{~K})-T_{b}$ correlation are evaluated as $\pm 1.5 \mathrm{~kJ} \cdot \mathrm{mol}^{-1}$. Finally, with Equation (5) we estimated the enthalpies 
of vaporization of ethyl, n-propyl, and n-butyl-substituted pyridines and quinolines for which vapor pressure measurements were not available.

\subsubsection{Validation Using the Group-Additivity Principles: "Centerpiece Approach"}

In series of our recent papers $[46,47]$ we are developing a so-called "centerpiece" approach, which is closely related to the conventional group-additivity (GA) methods $[48,49]$. In the GA methods, the enthalpy of a molecule of interest is collected from small groups (or "Lego bricks") with well-defined energetic contributions. In contrast, the idea of this "centerpiece" approach is to select a potentially large "core" molecule that may mimic the structure of the molecule of interest, but the selected "core" molecule has the wellestablished thermodynamic properties.

Various substituents can be attached (or subtracted) to this "centerpiece" in different positions. The visualization of the "centerpiece" approach for ethyl-quinolines is given in Figure 2.

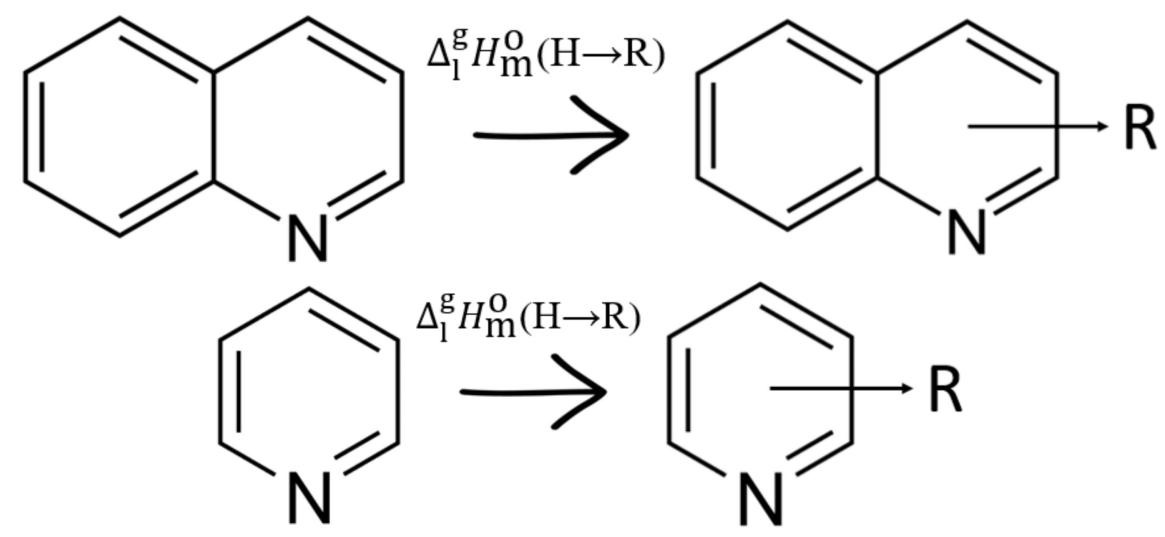

Figure 2. Calculation of vaporization enthalpies, $\Delta_{l}^{g} H_{\mathrm{m}}^{\mathrm{o}}(298.15 \mathrm{~K})$, of ethyl-substituted quinolines using the "centerpiece approach".

For the calculation, e.g., the enthalpy of vaporization of 2-ethyl-quinoline, a similarly shaped unsubstituted quinoline can be taken as a possible "centerpiece" with a reliable experimental $\Delta_{1}^{\mathrm{g}} H_{\mathrm{m}}^{\mathrm{o}}(298.15 \mathrm{~K})$-value (see Table 2). It is obvious that quinoline rings already bear the main energetic contribution to the vaporization enthalpy due to the interactions of aromatic rings in the liquid phase. Such a specific contribution is unique to the quinoline as the "centerpiece" molecule and cannot be captured by any other method. This special feature of the "centerpiece" approach significantly increases the reliability of the property prediction for similarly shaped molecules, e.g., ethyl-quinolines. In order to estimate the vaporization enthalpy of 2-ethyl-quinoline, we use the well-known $\Delta_{1}^{\mathrm{g}} H_{\mathrm{m}}^{\mathrm{o}}(298.15 \mathrm{~K})$ value of quinoline as the "centerpiece", and add the contribution for the ethyl-substituent as it shown in Figure 2. The contribution for the ethyl group can be easily derived as the difference between vaporization enthalpy of 2-, 3-, or 4-ethyl-pyridine and enthalpy of vaporization of unsubstituted pyridine (see Figure 2). To validate the "centerpiece" approach for quinoline derivatives, we calculated enthalpies of vaporization of 2-ethylquinoline, 3-ethyl-quinoline, and 4-ethyl-quinoline (see Table 2, labeled as GA) and these values agree within $\pm 1 \mathrm{~kJ} \cdot \mathrm{mol}^{-1}$ with results derived from other methods.

\subsubsection{Validation Using the Correlation with the Number of C-Atoms $\left(\mathrm{N}_{\mathrm{C}}\right)$ in the Alkyl Chain}

The final check to establish the internal consistency of the experimental results evaluated in Table 3 for alkyl-pyridines is to correlate the $\Delta_{1}^{\mathrm{g}} H_{\mathrm{m}}^{\mathrm{o}}(298.15 \mathrm{~K})$-values with the number of $\mathrm{C}$-atoms $\left(N_{C}\right)$ in the alkyl chain. As a rule, the simple linear correlation type is observed in all homologous series regardless of the functional group attached to the alkyl chain [50]. In addition, for the alkyl-substituted pyridines the $\Delta_{1}^{\mathrm{g}} H_{\mathrm{m}}^{\mathrm{o}}(298.15 \mathrm{~K})$ correlates with $N_{C}=0-4$ as follows: 


$$
\begin{aligned}
& \text { 2- alkyl - pyridines : } \Delta_{1}^{\mathrm{g}} H_{\mathrm{m}}^{\mathrm{o}}(298.15 \mathrm{~K}) /\left(\mathrm{kJ} \cdot \mathrm{mol}^{-1}\right)=39.5+3.57 \times N_{\mathrm{C}} \text { with }\left(R^{2}=0.9881\right) \\
& 3 \text { - alkyl - pyridines : } \Delta_{1}^{\mathrm{g}} H_{\mathrm{m}}^{\mathrm{o}}(298.15 \mathrm{~K}) /\left(\mathrm{kJ} \cdot \mathrm{mol}^{-1}\right)=40.3+4.07 \times N_{\mathrm{C}} \text { with }\left(R^{2}=0.9939\right) \\
& 4 \text { - alkyl - pyridines : } \Delta_{1}^{\mathrm{g}} H_{\mathrm{m}}^{\mathrm{o}}(298.15 \mathrm{~K}) /\left(\mathrm{kJ} \cdot \mathrm{mol}^{-1}\right)=40.6+3.91 \times N_{\mathrm{C}} \text { with }\left(R^{2}=0.9960\right)
\end{aligned}
$$

This good correlation quality can be seen as the final validation of the experimental data on the $\Delta_{1}^{\mathrm{g}} H_{\mathrm{m}}^{\mathrm{o}}(298.15 \mathrm{~K})$ evaluated in this work. Moreover, using Equations (6)-(8), the enthalpies of vaporization of pyridines with longer alkyl chain could be estimated.

\subsection{Gas-Phase Standard Molar Enthalpies of Formation of Alkyl-Quinolines and Alkyl-Pyridines}

The standard molar enthalpies of formation, $\Delta_{\mathrm{f}} H_{\mathrm{m}}^{\mathrm{o}}$, are an essential part of thermodynamic information that is required to optimize of the heat management in chemical technology. The available for quinolines enthalpies of formation in the condensed phase, $\Delta_{\mathrm{f}} H_{\mathrm{m}}^{\mathrm{o}}$ (cr or liq), are collected and averaged in Table 9, column 2. These data were used together with the vaporization enthalpies of quinolines, which evaluated and averaged in this work (see Table 2) to derive the experimental gas-phase standard molar enthalpies of

\begin{tabular}{|c|c|c|c|c|}
\hline Compound & $\Delta_{\mathrm{f}} H_{\mathrm{m}}^{\mathrm{o}}(\mathrm{liq}$ or cr) & $\Delta_{\mathrm{l}, \mathrm{cr}}^{\mathrm{g}} H_{\mathrm{m}}^{\mathrm{o}} \mathbf{b}$ & $\Delta_{\mathrm{f}} H_{\mathrm{m}}^{\mathrm{o}}(\mathrm{g}) \exp$ & $\Delta_{\mathrm{f}} H_{\mathrm{m}}^{\mathrm{o}}(\mathrm{g})_{\text {theor }}{ }^{\mathrm{c}}$ \\
\hline 1 & 2 & 3 & 4 & 5 \\
\hline quinoline (liq) & $141.2 \pm 0.9[14]$ & $59.3 \pm 0.4$ & $200.5 \pm 1.0$ & 198.1 \\
\hline \multirow[t]{2}{*}{ 2-methylquinoline (liq) } & $\begin{array}{l}93.0 \pm 2.5[17] \\
95.2 \pm 0.9[18]\end{array}$ & & & \\
\hline & $94.9 \pm 0.8^{\mathrm{d}}$ & $61.7 \pm 0.3$ & $156.6 \pm 0.9$ & 155.6 \\
\hline 4-methylquinoline (liq) & $94.5 \pm 2.6[17]$ & $64.1 \pm 0.4$ & $158.6 \pm 2.7$ & 161.3 \\
\hline 6-methylquinoline (liq) & $93.3 \pm 2.4[17]$ & $64.0 \pm 0.3[17]$ & $157.3 \pm 2.4$ & 163.3 \\
\hline \multirow[t]{3}{*}{ 8-methylquinoline (liq) } & $102.0 \pm 2.4[17]$ & & & \\
\hline & $103.2 \pm 1.6[18]$ & & & \\
\hline & $102.8 \pm 1.3^{\mathrm{d}}$ & $62.0 \pm 0.3[18]$ & $164.8 \pm 1.3$ & 161.4 \\
\hline \multirow[t]{3}{*}{ 2,6-dimethylquinoline (cr) } & $36.4 \pm 2.5[51]$ & & & \\
\hline & $36.2 \pm 0.9[34]$ & & & \\
\hline & $36.2 \pm 0.8^{\mathrm{d}}$ & $85.1 \pm 0.4[34]$ & $121.3 \pm 0.9$ & 121.3 \\
\hline 2,7-dimethylquinoline (cr) & $34.3 \pm 2.6[51]$ & $85.5 \pm 1.6[51]$ & $119.8 \pm 3.1$ & 120.6 \\
\hline 2-phenylquinoline (cr) & $181.8 \pm 3.9[20]$ & $104.8 \pm 2.2$ & $286.6 \pm 4.5$ & - \\
\hline
\end{tabular}
formation, $\Delta_{\mathrm{f}} H_{\mathrm{m}}^{\mathrm{o}}(\mathrm{g})_{\exp }$ at $298.15 \mathrm{~K}$ (see Table 9, column 4).

Table 9. Thermochemical data for quinolines at $T=298.15 \mathrm{~K}\left(p^{\circ}=0.1 \mathrm{MPa}\right.$, in $\left.\mathrm{kJ} \cdot \mathrm{mol}^{-1}\right)$ a

${ }^{a}$ The uncertainties are given as twice the standard deviation. Values given in bold are recommended for thermochemical calculations.

${ }^{b}$ Evaluated experimental values from Table 2. ${ }^{c}$ Theoretical value calculated using the G4 method (see Table 10). ${ }^{d}$ Weighted average from data given in this table (experimental uncertainties used as the weighing factor).

In the last decade we systematically used the high-level quantum-chemical calculations for the mutual validation of $\Delta_{\mathrm{f}} H_{\mathrm{m}}^{\mathrm{o}}(\mathrm{g}, 298.15 \mathrm{~K})$-values obtained from the experimental and computational thermochemistry. The recent development of the high-level composite methods has led to computation of the gas-phase enthalpies of formation with a "chemical accuracy" that is commonly defined as $\pm 4-5 \mathrm{~kJ} \cdot \mathrm{mol}^{-1}$ [52-54]. An agreement or disagreement between the theoretical and experimental $\Delta_{\mathrm{f}} H_{\mathrm{m}}^{\mathrm{o}}(\mathrm{g}, 298.15 \mathrm{~K})$-values serves as an indicator of the consistency and reliability for both results, the prerequisite for the use of thermochemical data in chemical technology. We used the experimental $\Delta_{\mathrm{f}} H_{\mathrm{m}}^{\mathrm{o}}$ ( $\mathrm{g}, 298.15 \mathrm{~K}$ )-values from Table 9 together with the evaluated experimental gas-phase enthalpies of formation of alkyl-pyridines [55] to validate the high-level quantum-chemical method G4 for the reliable calculation of the alkyl-substituted pyridines and quinolines. 
Quinolines and pyridines are rigid molecules with no conformational flexibility. Stable conformers were found by using the force field method MM3 [56] and optimized with the B3LYP / 6-31g $(\mathrm{d}, \mathrm{p})$ method [57]. The energies $E_{0}$ and the enthalpies $H_{298}$ of the most stable conformers were calculated by using the G4 method [5] from the Gaussian 16 suit of programs [6]. There are several ways of converting the $H_{298}$ values, which are available directly from the output of the Gaussian 16 into the theoretical standard enthalpies of formation $\Delta_{\mathrm{f}} H_{\mathrm{m}}^{\mathrm{o}}(\mathrm{g})$. In this work, we calculated the gaseous enthalpies of formation of alkyl-substituted quinolines and pyridines using an atomization reaction. From our experience with the composite methods, we have found that for the molecules containing $\mathrm{C}, \mathrm{H}$, and $\mathrm{N}$ atoms the enthalpies of formation derived from the atomization procedure slightly, but systematically, deviate from the experimental values (see Table 10).

Table 10. Results of calculation of enthalpies of formation of alkyl-quinolines and alkyl-pyridines calculated with the G4 method at $T=298.15 \mathrm{~K}\left(p^{\circ}=0.1 \mathrm{MPa} \text {, in } \mathrm{kJ} \cdot \mathrm{mol}^{-1}\right)^{\mathrm{a}}$.

\begin{tabular}{|c|c|c|c|c|c|}
\hline CAS & Compound & $\Delta_{\mathrm{f}} H_{\mathrm{m}}^{\mathrm{o}}(\mathrm{g})_{\mathrm{AT}}{ }^{\mathrm{a}}$ & $\Delta_{\mathrm{f}} H_{\mathrm{m}}^{\mathrm{o}}(\mathrm{g}) \exp [55]$ & $\Delta_{\mathrm{f}} H_{\mathrm{m}}^{\mathrm{o}}(\mathrm{g})_{\text {theor }} \mathrm{b}$ & $\Delta^{\mathrm{c}}$ \\
\hline $110-86-1$ & pyridine & 139.1 & 140.4 & 141.3 & -0.9 \\
\hline $109-06-8$ & 2-methylpyridine & 97.4 & 99.2 & 100.1 & -0.9 \\
\hline $108-99-6$ & 3-methylpyridine & 104.5 & 106.4 & 107.1 & -0.7 \\
\hline $108-89-4$ & 4-methylpyridine & 102.2 & 104.1 & 104.8 & -0.7 \\
\hline $583-61-9$ & 2,3-dimethylpyridine & 63.2 & 68.3 & 66.2 & 2.1 \\
\hline $108-47-4$ & 2,4-dimethylpyridine & 60.6 & 63.9 & 63.7 & 0.2 \\
\hline $589-93-5$ & 2,5-dimethylpyridine & 63.6 & 66.5 & 66.6 & -0.1 \\
\hline $108-48-6$ & 2,6-dimethylpyridine & 55.8 & 58.7 & 58.9 & -0.2 \\
\hline $583-58-4$ & 3,4-dimethylpyridine & 66.7 & 70.7 & 69.7 & 1.0 \\
\hline $591-22-0$ & 3,5-dimethylpyridine & 70.3 & 72.8 & 73.2 & -0.4 \\
\hline $91-22-5$ & quinoline & 196.5 & $200.5^{\mathrm{d}}$ & 198.1 & 2.4 \\
\hline $91-63-4$ & 2-methylquinoline & 153.5 & $156.6^{d}$ & 155.6 & 1.0 \\
\hline $612-58-8$ & 3-methylquinoline & 161.2 & & 163.2 & \\
\hline $491-35-0$ & 4-methylquinoline & 159.3 & $158.6^{d}$ & 161.3 & -2.7 \\
\hline $91-62-3$ & 6-methylquinoline & 161.3 & & 163.3 & \\
\hline $611-32-3$ & 8-methylquinoline & 159.4 & & 161.4 & \\
\hline $877-43-0$ & 2,6-dimethylquinoline & 118.9 & $121.3^{\mathrm{d}}$ & 121.3 & 0.0 \\
\hline $93-37-8$ & 2,7-dimethylquinoline & 118.2 & $119.8^{d}$ & 120.6 & -0.8 \\
\hline $100-71-0$ & 2-ethylpyridine & 75.6 & & 78.5 & \\
\hline $536-78-7$ & 3-ethylpyridine & 82.9 & & 85.7 & \\
\hline $536-75-4$ & 4-ethylpyridine & 80.6 & & 83.4 & \\
\hline $1613-34-9$ & 2-ethylquinoline & 131.9 & & 134.2 & \\
\hline $1873-54-7$ & 3-ethylquinoline & 139.5 & & 141.7 & \\
\hline $19020-26-9$ & 4-ethylquinoline & 139.6 & & 141.8 & \\
\hline
\end{tabular}

${ }^{a}$ Calculated by the G4 method according to the standard atomization procedure. ${ }^{\mathrm{b}}$ Results from atomization reaction were corrected with help of following equation: $\Delta_{\mathrm{f}} H_{m}^{o}(\mathrm{~g})_{\text {theor }} / \mathrm{kJ} \cdot \mathrm{mol}^{-1}=0.9893 \times \Delta_{\mathrm{f}} H_{m}^{o}(\mathrm{~g}, \mathrm{AT})+3.7$ with $R^{2}=0.9991$ (the expanded uncertainty assessed to be $\pm 3.5 \mathrm{~kJ} \cdot \mathrm{mol}^{-1}$ ) [5]. ${ }^{\mathrm{c}}$ Difference between column 4 and 5 in this table. ${ }^{\mathrm{d}}$ Taken from Table 9 , column 4 .

Fortunately, it turned out that for each composite method a simple linear correlation could be found between the enthalpies of formation calculated by the atomization method and those from the experiment. These linear correlations can be used to "correct" the theoretical $\Delta_{\mathrm{f}} H_{\mathrm{m}}^{\mathrm{o}}(\mathrm{g})$-values calculated by the atomization procedure. In this work we established the following linear correlations:

$$
\Delta_{f} H_{m}^{o}(\mathrm{~g})_{\text {theor }} / \mathrm{kJ} \cdot \mathrm{mol}^{-1}=0.9893 \times \Delta_{\mathrm{f}} H_{m}^{o}(\mathrm{~g}, \mathrm{AT})+3.7 \text { with } R^{2}=0.9991
$$

The experimental data used to establish this correlation are given in Table 10 (column 4).

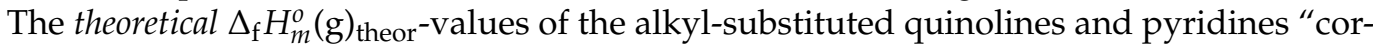
rected" in this way (see Table 10, column 5) were found to be in close agreement with the experimental one. A good agreement between the theoretical and experimental $\Delta_{\mathrm{f}} H_{m}^{o}(\mathrm{~g}$, 298.15 K)-values for the alkyl-substituted quinolines and pyridines is apparent from this table. This agreement has helped to establish the general consistency in the available 
experimental results on $\Delta_{\mathrm{f}} H_{m}^{o}$, as well as in the vaporization enthalpies and to recommend the experimental data evaluated in Table 2, Table 3, and Table 10 as the reliable benchmark properties for further thermochemical calculations in Section 3.5.

\subsection{Thermodynamic Analysis of the Hydrogenation/Dehydrogenation Reactions}

In general, the heterocyclic aromatic compounds are being studied intensively as future-oriented LOHC, as the presence of a heteroatom in the LOHC minimizes the unfavorable thermodynamics of the dehydrogenation reaction and enables both hydrogenation and dehydrogenation under mild conditions. The major advantage of hetero-cycles over homo-cyclic aromatics is the significantly lower enthalpy of reaction for the release of hydrogen through dehydrogenation. For this reason, the reliable numerical values of the reaction enthalpies of the hydrogenation/dehydrogenation reactions are crucial for the comparison of potential LOHC and the selection of the best one for practical application. In order to derive the reaction enthalpies of the hydrogenation/dehydrogenation (see R1-R3, Figure 1) according to Hess's Law, the standard molar enthalpies of formation of the reaction participants are required. In the hydrogen storage technologies, the reactants are defined as "hydrogen lean" compounds (alkyl-pyridines and alkyl-quinolines in this work) and as "hydrogen reach" compounds (fully hydrogenated alkyl-pyridines and alkyl-quinolines in this work).

\subsubsection{Liquid-Phase Standard Molar Enthalpies of Formation of the "Hydrogen Lean"} Reactants

In Section 3.4 it was shown that the G4 method provides reliable $\Delta_{\mathrm{f}} H_{m}^{o}(\mathrm{~g}, 298.15 \mathrm{~K})$ values for the "hydrogen lean" alkyl-substituted pyridines and quinolines (see Table 10). It is therefore advantageous to use this method for a comprehensive analysis of the thermodynamics of the hydrogenation/dehydrogenation reactions (see reactions 1 to 3 in the Introduction) with these potential liquid organic hydrogen carriers. In hydrogen storage technology, however, the hydrogenation/dehydrogenation reactions are carried out in the liquid phase and not in the gaseous state, where quantum chemistry offers a noteworthy aid. However, our previous studies $[53,54]$ convince that data on enthalpies of formation in the liquid phase can be obtained accurately according to the following equation:

$$
\Delta_{\mathrm{f}} H_{m}^{o}(\mathrm{liq}, 298.15 \mathrm{~K})=\Delta_{\mathrm{f}} H_{m}^{o}(\mathrm{~g}, 298.15 \mathrm{~K})-\Delta_{l}^{g} H_{m}^{o}(298.15 \mathrm{~K})
$$

by using enthalpies of formation in the gas phase calculated with high-level quantumchemical methods, along with experimental data on enthalpies of vaporization. In order to derive the liquid-phase enthalpies of formation of the "hydrogen lean" alkyl-substituted pyridines and quinolines according to Equation (10) we used the gas-phase enthalpies of formation calculated with the G4 method (see Table 10) and the vaporization enthalpies of these compounds evaluated in Table 2 and 3. The liquid-phase enthalpies of the "hydrogen lean" reactants calculated in this way are given in Table 11, column 4. 
Table 11. Calculation of the liquid-phase reaction enthalpies, $\Delta_{\mathrm{r}} H_{m}^{o}$ (liq), of the dehydrogenation of pyridines to piperidines and quinolines to decahydroquinolines, at $T=298.15 \mathrm{~K}\left(p^{\circ}=0.1 \mathrm{MPa}\right.$, in $\left.\mathrm{kJ} \cdot \mathrm{mol}^{-1}\right){ }^{\mathrm{a}}$.

\begin{tabular}{|c|c|c|c|c|c|c|}
\hline Compound & $\Delta_{\mathrm{f}} H_{\mathrm{m}}^{\mathrm{o}}$ (gas) ${ }_{\mathrm{HL}}{ }^{\mathrm{a}}$ & $\Delta_{1}^{\mathrm{g}} H_{\mathrm{m}}^{\mathrm{o}} \mathrm{b}$ & $\Delta_{\mathrm{f}} H_{\mathrm{m}}^{\mathrm{o}}(\mathrm{liq})_{\mathrm{HL}}^{\mathrm{c}}$ & $\Delta_{\mathrm{f}} H_{\mathrm{m}}^{\mathrm{o}}(\mathrm{liq})_{\mathrm{HL}}^{\mathrm{d}}$ & $\Delta_{\mathrm{r}} H_{\mathrm{m}}^{\mathrm{o}}(\mathrm{liq})^{\mathrm{e}}$ & $\Delta_{\mathrm{r}} H_{\mathrm{m}}^{\mathrm{o}}(\mathrm{liq}) / \mathrm{H}_{2} \mathrm{f}$ \\
\hline 1 & 2 & 3 & 4 & 5 & 6 & 7 \\
\hline pyridine [55] & 139.1 & 40.2 & 98.9 & -86.4 & -185.3 & -61.8 \\
\hline 2-methylpyridine [55] & 97.4 & 42.5 & 54.9 & -124.9 & -179.8 & -59.9 \\
\hline 3-methylpyridine [55] & 104.5 & 44.6 & 59.9 & -123.6 & -183.5 & -61.2 \\
\hline 4-methylpyridine [55] & 102.2 & 44.8 & 57.4 & -123.5 & -180.9 & -60.3 \\
\hline 2-ethylpyridine & 78.5 & 45.9 & 32.6 & -158.0 & -190.6 & -63.5 \\
\hline 3-ethylpyridine & 85.7 & 48.0 & 37.7 & -158.0 & -195.7 & -65.2 \\
\hline 4-ethylpyridine & 83.4 & 48.6 & 34.8 & -158.0 & -192.8 & -64.3 \\
\hline quinoline [14] & 200.5 & 59.3 & 141.2 & -166.2 & -307.4 & -61.5 \\
\hline 2-methylquinoline & 155.6 & 61.7 & 93.9 & -204.0 & -297.9 & -59.5 \\
\hline 3-methylquinoline & 163.2 & 63.7 & 99.5 & -204.0 & -303.5 & -60.7 \\
\hline 4-methylquinoline & 161.3 & 64.1 & 97.2 & -204.0 & -301.2 & -60.2 \\
\hline 2-ethylquinoline & 134.2 & 64.2 & 70.0 & -237.8 & -307.8 & -61.6 \\
\hline 3-ethylquinoline & 141.7 & 66.8 & 74.9 & -237.8 & -312.7 & -62.5 \\
\hline 4-ethylquinoline & 141.8 & 67.7 & 74.1 & -237.8 & -311.9 & -62.4 \\
\hline 2-phenyl-quinoline & 286.6 & 92.7 & 193.9 & -283.3 & -477.2 & -59.7 \\
\hline
\end{tabular}

${ }^{\text {a }}$ Gas-phase enthalpies of formation of the fully dehydrogenated molecules are shown (HL = "hydrogen lean" = substituted pyridine or quinoline) from Table 10, column 5, or from experiment [55]. ${ }^{\mathrm{b}}$ Evaluated enthalpies of vaporization of the fully dehydrogenated molecules from Tables 2 and 3. ${ }^{c}$ Liquid-phase enthalpies of formation of the fully dehydrogenated molecules calculated according to Equation (10) as the difference between column 2 and 3 in this table. ${ }^{\mathrm{d}}$ Liquid-phase enthalpies of formation of the fully hydrogenated molecules

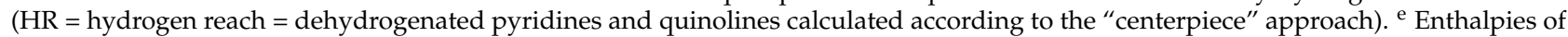
reactions according to Figure $1 .{ }^{\mathrm{f}}$ Enthalpies of reactions according to Figure 1 per mole $\mathrm{H}_{2}$.

\subsubsection{Liquid-Phase Standard Molar Enthalpies of Formation of the "Hydrogen Reach" Reactants}

The quantum-chemical methods such as the G4 method are also able to provide reliable $\Delta_{\mathrm{f}} H_{m}^{o}(\mathrm{~g}, 298.15 \mathrm{~K})$-values for the "hydrogen reach" reactant. For example, the thermodynamics and the hydrogenation/dehydrogenation equilibrium of biphenyl to bicyclohexyl were analyzed by the G4 method in full agreement with the thermochemical experiments [58]. However, the extensive application of quantum-chemical methods to calculate the fully dehydrogenated "hydrogen reach" reactants is thwarted with complications due to the abundant flexibility of these molecules. Even for the simplest "hydrogen reach" reactant cyclohexane, the textbook shows at least two stable and energetically significantly different conformations. For the larger molecules such as decahydroquinoline, the conformational energy diagram is more complex, and the number of possible energetically close conformers increases exponentially. All of these conformers contribute to the enthalpy of formation in the gas phase and their thermal population must be taken into account according to the Boltzmann distribution of conformers. Furthermore, the introduction of any substituent into such a cyclic system could cause the ring flipping and additional stable conformations to appear. As a consequence, the reliable determination of the reliable $\Delta_{\mathrm{f}} H_{m}^{o}(\mathrm{~g}, 298.15 \mathrm{~K})$-values for the "hydrogen reach" reactants becomes a time-consuming and computationally intensive task. In addition, the vaporization enthalpies of the perhydrogenated pyridines and quinolines required according to Equation (10) are not available and a reliable prediction of these values is not a trivial task either.

The "centerpiece" approach, which was already presented in Section 3.3.3, is not a remedy, but a practicable method for estimating the liquid-phase enthalpies of formation of the perhydrogenated species. Indeed, the "centerpieces", such as piperidine of decahydroquinoline, have reliable experimental $\Delta_{\mathrm{f}} H_{m}^{o}$ (liq, $298.15 \mathrm{~K}$ )-values (see Table S6). Different substituents can be attached to these "centerpieces" in different positions. The visualization of the "centerpiece" approach for the "hydrogen reach" pyridine derivatives is given in Figure 3 and for the "hydrogen reach" quinoline derivatives is given in Figures 4 and 5 . 
<smiles>CC1CCCNC1</smiles><smiles>CC1CCCCN1</smiles><smiles>C1CCNCC1</smiles><smiles>CC1CCNCC1</smiles>

$-37.8$
$-71.6$<smiles>CCC1CCCNC1</smiles><smiles>CCC1CC(C=CC2CC2)CCN1</smiles><smiles>CCC1CCNCC1</smiles>

Figure 3. Evaluation of increments $\mathrm{H} \rightarrow \mathrm{CH}_{3}$ for $\Delta_{\mathrm{f}} H_{\mathrm{m}}^{\mathrm{o}}$ (liq) responsible for exchange of $\mathrm{H}$-atom in piperidine ring with the methyl group. The averaged increment $(-37.8 \pm 0.8) \mathrm{kJ} \cdot \mathrm{mol}^{-1}$ for the $\mathrm{H} \rightarrow \mathrm{CH}_{3}$ substitution was derived as it shown in Figure S4. The increment $\mathrm{H} \rightarrow \mathrm{CH}_{2} \mathrm{CH}_{3}$ was calculated based on the enthalpies of formation of piperidine, 4-ethyl-piperidine (numerical data are given in Table S6).<smiles>CC1CCC2CCCCC2N1</smiles>

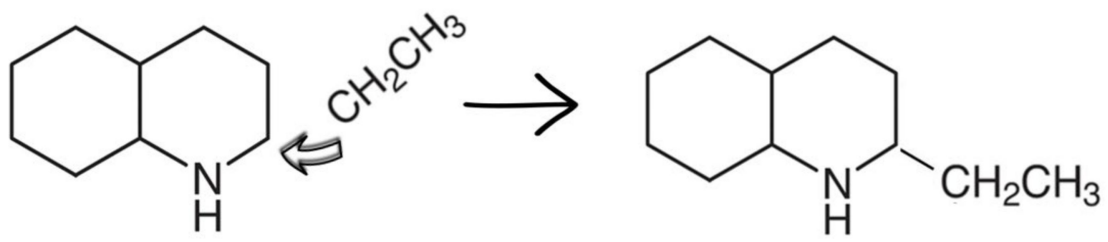

Figure 4. Calculation of enthalpies of formation, $\Delta_{\mathrm{f}} H_{\mathrm{m}}^{\mathrm{o}}(\mathrm{liq})$, of alkyl-substituted decahydroquinolines using the $\mathrm{H} \rightarrow \mathrm{CH}_{3}(-37.8 \pm 0.8)$ and $\mathrm{H} \rightarrow \mathrm{CH}_{2} \mathrm{CH}_{3}(-71.6 \pm 1.8)$ increments for piperidine ring (see Figure 3).<smiles>CC(C)(C)C1CCCCC1CSC1CCC2CCCCC2N1</smiles>

Figure 5. Calculation of enthalpy of formation, $\Delta_{\mathrm{f}} \mathrm{H}_{\mathrm{m}}^{\mathrm{o}}$ (liq), of cyclohexyl-substituted decahydroquinoline using the $\mathrm{H} \rightarrow$ cyclohexyl increment. The $\mathrm{H} \rightarrow$ cyclohexyl $=-117.1 \pm 1.7 \mathrm{~kJ} \cdot \mathrm{mol}^{-1}$ increment was calculated as difference $\Delta_{\mathrm{f}} H_{\mathrm{m}}^{\mathrm{o}}$ (liq, bicyclohexyl) $-\Delta_{\mathrm{f}} H_{\mathrm{m}}^{\mathrm{o}}$ (liq, cyclohexane), numerical data are given in Table S6. 
The liquid-phase enthalpies of formation of the "hydrogen reach" alkyl-pyridine and alkyl-quinoline derivatives, calculated according to the centerpiece approach (for details see Table S7), are given in Table 11, column 5. This means that all data for calculating the hydrogenation/dehydrogenation enthalpies for reactions according to R1-R3 (Figure 1) are complete.

\subsubsection{Liquid-Phase Enthalpies of the Hydrogenation/Dehydrogenation Reactions}

The enthalpy of hydrogenation/dehydrogenation reaction is an important quantity for the hydrogen storage. The $\Delta_{r} H_{m}^{o}$ (liq)-values calculated according to Hess's Law are given in Table 11, column 6. However, it seems unlikely that the enthalpies of hydrogenation in the gaseous state differ from the enthalpies in the liquid phase, since the enthalpies of vaporization of the reactants do not differ significantly. All reactions with substituted pyridines and quinolines are highly exothermic from -180 to $-477 \mathrm{~kJ} \cdot \mathrm{mol}^{-1}$. This means that extremely accurate enthalpies of reaction must be used for thermal management of hydrogen storage reactors with LOHC. Admittedly, in order to compare different LOHC, it is more useful to relate the enthalpies of reaction to the number of moles of hydrogen released during the dehydrogenation. These relative values per mole of $\mathrm{H}_{2}$ are given in Table 11, column 7. It has turned out that the enthalpies of reaction for pyridine and quinoline derivatives are not much different and are generally between -60 and $-65 \mathrm{~kJ} \cdot \mathrm{mol}^{-1} / \mathrm{H}_{2}$. These results are generally comparable with commercially available thermofluids benzyltoluenes (Marlothem $\mathrm{LH}^{\circledR},-63.5 \mathrm{~kJ} \cdot \mathrm{mol}^{-1} / \mathrm{H}_{2}$ ) [59], dibenzyltoluenes (Marlotherm SH${ }^{\circledR}$, $\left.-65.4 \mathrm{~kJ} \cdot \mathrm{mol}^{-1} / \mathrm{H}_{2}\right)[59]$ and biphenyl $\left(-65.4 \mathrm{~kJ} \cdot \mathrm{mol}^{-1} / \mathrm{H}_{2}\right)$ [40] reported in our previous studies. It is obvious that new results for pyridines and quinolines are not better than those of $N$-ethylcarbazole $\left(-50.5 \mathrm{~kJ} \cdot \mathrm{mol}^{-1} / \mathrm{H}_{2}[60]\right)$, indole $\left(-56.6 \mathrm{~kJ} \mathrm{~mol}^{-1} / \mathrm{H}_{2}[61]\right)$ and for 2-methyl indole $\left(-55.2 \mathrm{~kJ} \mathrm{~mol}^{-1} / \mathrm{H}_{2}[61]\right)$.

It was found that the reaction enthalpy for 2-phenyl-quinoline $\left(-59.7 \mathrm{~kJ} \cdot \mathrm{mol}^{-1} / \mathrm{H}_{2}\right.$, see Table 11) is one of the lowest among the substituted pyridines and quinolines investigated in this work. For comparison: the reaction enthalpy of $N$-phenyl-carbazole $\left(-57.7 \mathrm{~kJ} \cdot \mathrm{mol}^{-1} / \mathrm{H}_{2}\right)$ [44] is very close to that of 2-phenyl-quinoline, but significantly higher than that of $N$-alkyl-carbazoles ( -50.5 for ethyl-, -49.4 for iso-propyl-, -50.4 for n-propyl-, and for n-butyl $-50.4 \mathrm{~kJ} \cdot \mathrm{mol}^{-1} / \mathrm{H}_{2}$, respectively) [62]. Even if the reaction enthalpies of the hydrogenation/dehydrogenation enthalpies of phenyl-substituted LOHC do not differ significantly from those with aliphatic chains, the presence of the phenyl ring in the structure increases the $\mathrm{H}_{2}$ storage capacity and makes such compounds more interesting for practical applications.

Supplementary Materials: The following are available online at https: / www.mdpi.com/article / 10.3390/app112411758/s1, Figure S1: Temperature dependence of vapor pressures over the 2-methylquinoline, Figure S2: Temperature dependence of vapor pressures over the 3-methyl-quinoline, Figure S3: Temperature dependence of vapor pressures over the 4-methyl-quinoline, Figure S4: Evaluation of increments responsible for the exchange of $\mathrm{H}$-atom in piperidine ring with the methyl group. Table S1: Provenance and purity of samples used in this work; Table S2: Compilation of data on molar heat capacities of pyridines and quinolines; Table S3: Coefficients of the Clarke and Glew equation; Table S4: Vapour pressures at different temperatures collected from SciFinder, standard molar vaporization enthalpies and standard molar vaporization entropies; Table S5: Compilation of enthalpies of fusion of quinoline derivatives; Table S6: Thermochemical data for reference compounds; Table S7: Calculation of the liquid phase enthalpies of the decahydroquinolines.

Author Contributions: Conceptualization, S.P.V. and A.A.S.; methodology, S.P.V., A.A.S. and S.V.V.; software, A.A.S.; validation, S.P.V., A.A.S. and S.V.V.; formal analysis, S.P.V., A.A.S. and S.V.V.; investigation, S.P.S., data curation S.P.S.; writing-original draft preparation, S.P.V., A.A.S. and S.V.V.; writing-review and editing, S.P.V., A.A.S. and S.V.V.; visualization, S.P.S.; supervision, S.P.V.; project administration, S.P.V.; funding acquisition, S.P.V. All authors have read and agreed to the published version of the manuscript. 
Funding: This research was funded by the Ministry of Science and Higher Education of the Russian Federation (theme No. AAAA- A12-1111100072-9as) as part of the state task of the Samara State Technical University (creation of new youth laboratories); by the Government of Russian Federation (decree No. 220 of 9 April 2010), agreement No. 14.Z50.31.0038. S.P.V. acknowledges financial support from the German Science Foundation in the frame of SPP 1807 "Control of London Dispersion Interactions in Molecular Chemistry", grant VE 265-9/2.

Data Availability Statement: Data is contained within the article or Supplementary Materials.

Acknowledgments: Two of us (S.P.S.) and (A.A.S) acknowledge gratefully a research scholarship from the DAAD (Deutscher Akademischer Austauschdienst).

Conflicts of Interest: The authors declare no conflict of interest.

\section{References}

1. Preuster, P.; Papp, C.; Wasserscheid, P. Liquid Organic Hydrogen Carriers (LOHCs): Toward a Hydrogen-free Hydrogen Economy. Acc. Chem. Res. 2017, 50, 74-85. [CrossRef] [PubMed]

2. Collin, G.; Höke, H. Quinoline and Isoquinoline. In Ullmann's Encyclopedia of Industrial Chemistry; Wiley-VCH Verlag GmbH \& Co. KGaA: Weinheim, Germany, 2000; pp. 1-5.

3. Kulikov, D.; Verevkin, S.P.; Heintz, A. Determination of Vapor Pressures and Vaporization Enthalpies of the Aliphatic Branched C 5 and C 6 Alcohols. J. Chem. Eng. Data 2001, 46, 1593-1600. [CrossRef]

4. Verevkin, S.P.; Emel'yanenko, V.N. Transpiration method: Vapor pressures and enthalpies of vaporization of some low-boiling esters. Fluid Phase Equilib. 2008, 266, 64-75. [CrossRef]

5. Curtiss, L.A.; Redfern, P.C.; Raghavachari, K. Gaussian-4 theory. J. Chem. Phys. 2007, 126, 084108. [CrossRef] [PubMed]

6. Frisch, M.J.; Trucks, G.W.; Schlegel, H.B.; Scuseria, G.E.; Robb, M.A.; Cheeseman, J.R.; Scalmani, G.; Barone, V.; Petersson, G.A.; Nakatsuji, H.; et al. Gaussian 16, Revision C.01; Gaussian, Inc.: Wallingford, CT, USA, 2016.

7. Verevkin, S.P.; Sazonova, A.Y.; Emel'yanenko, V.N.; Zaitsau, D.H.; Varfolomeev, M.A.; Solomonov, B.N.; Zherikova, K.V. Thermochemistry of Halogen-Substituted Methylbenzenes. J. Chem. Eng. Data 2015, 60, 89-103. [CrossRef]

8. Emel'yanenko, V.N.; Verevkin, S.P. Benchmark thermodynamic properties of 1,3-propanediol: Comprehensive experimental and theoretical study. J. Chem. Thermodyn. 2015, 85, 111-119. [CrossRef]

9. Samarov, A.A.; Verevkin, S.P. Hydrogen storage technologies: Methyl-substituted biphenyls as an auspicious alternative to conventional liquid organic hydrogen carriers (LOHC). J. Chem. Thermodyn. 2022, 165, 106648. [CrossRef]

10. Verevkin, S.P.; Andreeva, I.V.; Konnova, M.E.; Portnova, S.V.; Zherikova, K.V.; Pimerzin, A.A. Paving the way to the sustainable hydrogen storage: Thermochemistry of amino-alcohols as precursors for liquid organic hydrogen carriers. J. Chem. Thermodyn. 2021, 163, 106610. [CrossRef]

11. SciFinder-Chemical Abstracts Service. Available online: http:/ / scifinder.cas.org/ (accessed on 15 November 2021).

12. Stephenson, R.M.; Malanowski, S. Handbook of the Thermodynamics of Organic Compounds; Elsevier: New York, NY, USA, 1987; ISBN 978-94-010-7923-5. [CrossRef]

13. Malanowski, S. Vapour Pressures and Boiling Temperatures of Some Quinoline Bases. Bull. Acad. Pol. Sci. Ser. Sci. Chim. 1961, 9 , 71-76.

14. Steele, W.V.; Archer, D.G.; Chirico, R.D.; Collier, W.B.; Hossenlopp, I.A.; Nguyen, A.; Smith, N.K.; Gammon, B.E. The thermodynamic properties of quinoline and isoquinoline. J. Chem. Thermodyn. 1988, 20, 1233-1264. [CrossRef]

15. Stull, D.R. Vapor Pressure of Pure Substances. Organic and Inorganic Compounds. Ind. Eng. Chem. 1947, 39, 517-540. [CrossRef]

16. Van de Rostyne, C.; Prausnitz, J.M. Vapor pressures of some nitrogen-containing, coal-derived liquids. J. Chem. Eng. Data 1980, 25, 1-3. [CrossRef]

17. Ribeiro da Silva, M.A.V.; Matos, M.A.R.; Amaral, L.M.P.F. Thermochemical study of 2-, 4-, 6-, and 8-methylquinoline. J. Chem. Thermodyn. 1995, 27, 565-574. [CrossRef]

18. Chirico, R.D.; Steele, W.V. Thermodynamic Properties of 2-Methylquinoline and 8-Methylquinoline. J. Chem. Eng. Data 2005, 50, 697-708. [CrossRef]

19. Lipkind, D.; Rath, N.; Chickos, J.S.; Pozdeev, V.A.; Verevkin, S.P. The Vaporization Enthalpies of 2- and 4-(N, NDimethylamino)pyridine, 1,5-Diazabicyclo[4.3.0]non-5-ene, 1,8-Diazabicyclo[5.4.0]undec-7-ene, Imidazo[1,2-a]pyridine and 1,2,4-Triazolo[1,5-a]pyrimidine by Correlation-Gas Chromatography. J. Phys. Chem. B 2011, 115, 8785-8796. [CrossRef] [PubMed]

20. Ribeiro da Silva, M.A.V.; Matos, M.A.R.; Amaral, L.M.P.F. Enthalpies of combustion, vapour pressures, and enthalpies of sublimation of 2-phenylquinoline and 2,2'-biquinoline. J. Chem. Thermodyn. 1997, 29, 1129-1136. [CrossRef]

21. Majer, V.; Svoboda, V. Enthalpies of Vaporization of Organic Compounds: A Critical Review and Data Compilation, Blackwell Scientific Publications; Blackwell Scientific: Oxford, UK, 1985.

22. Carraro, G.; Biasin, L.; Garbuglio, C. Mikromethode zur Dampfdruckbestimmung. Fresenius' Z. Anal. Chem. 1964, $204,172-176$. [CrossRef] 
23. Morais, V.M.F.; Miranda, M.S.; Matos, M.A.R. Thermochemical study of the ethylpyridine and ethylpyrazine isomers. Org. Biomol. Chem. 2003, 1, 4329. [CrossRef] [PubMed]

24. Sakoguchi, A.; Ueoka, R.; Kato, Y.; Arai, Y. Vapor Pressures of Pyridine and Alkylpyridines. Kagaku Kogaku Ronbunshu 1991, 17, 1218-1221. [CrossRef]

25. Frolov, A.F.; Loginova, M.A.; Kiselev, M.M. Saturated Vapor Pressure and Vapor-Liquid Equilibrium of the System 2-Methyl-5Vinylpyridine-2-Methyl-5-Ethylpyridine. Zh. Fiz. Khim. J. Phys. Chem. USSR 1961, 35, 1784-1788.

26. Gubareva, A.I.; Gerasimov, P.A.; Tarbeyeva, N.A.; Kunderenko, V.M. Physicochemical Properties of 2-methyl-5-ethylpyridine. Khim.-Farm. Zh. 1992, 26, 40-41. [CrossRef]

27. Dmitrikov, V.P.; Nabivach, V.M. Physico-chemical regularities of quinoline bases retention in gas chromatography. Coke Chem. (Engl. Transl.) 1995, 8, 27-34.

28. Pacáková, V.; Felti, L. Chromatographic Retention Indices: An Aid to Identification of Organic Compounds (Ellis Horwood Series in Analytical Chemistry); Ellis Horwood Ltd: New York, NY, USA, 1992.

29. Li, R.; Gao, S.-G.; Xiang, B.-R. Using improved BP neural network in predicting GC retention indices. Comput. Appl. Chem. 2000, $17,113-114$.

30. Bark, L.S.; Wheatstone, K.C. Studies in the relationship between molecular structure and chromatographic behaviour. J. Chromatogr. A 1974, 92, 281-289. [CrossRef]

31. Greenberg, M.J. Characterization of poultry by-product meal flavor volatiles. J. Agric. Food Chem. 1981, 29, 831-834. [CrossRef]

32. Verevkin, S.P. Vapour pressures and enthalpies of vaporization of a series of the linear n-alkyl-benzenes. J. Chem. Thermodyn. 2006, 38, 1111-1123. [CrossRef]

33. Malanowska, B.; Wecsile, J. Vapour Pressures and Boiling Temperatures of Some Quinoline Bases. Bull. Acad. Pol. Sci. Ser. Sci. Chim. 1964, 12, 239-241.

34. Chirico, R.D.; Johnson, R.D.; Steele, W.V. Thermodynamic properties of methylquinolines: Experimental results for 2,6dimethylquinoline and mutual validation between experiments and computational methods for methylquinolines. $J$. Chem. Thermodyn. 2007, 39, 698-711. [CrossRef]

35. Hasegawa, K.; Usami, S.; Higashide, A. Analysis of amino polycyclic hydrocarbons and polycyclic aromatic nitrogen heterocycles in the basic fraction of coal-derived oil. Nippon Kagaku Kaishi 1990, 223, 777-788. [CrossRef]

36. Reckendorf, R.M. Identification of phenyl-substituted polycyclic aromatic compounds in ring furnace gases using GC-MS and GC-AED. Chromatographia 1997, 45, 173-182. [CrossRef]

37. Surov, A.O.; Perlovich, G.L.; Emel'yanenko, V.N.; Verevkin, S.P. Thermochemistry of Drugs. Experimental and First-Principles Study of Fenamates. J. Chem. Eng. Data 2011, 56, 4325-4332. [CrossRef]

38. Verevkin, S.P.; Georgieva, M.; Melkhanova, S.V. Vapor Pressures and Phase Transitions of a Series of the Aminonaphthalenes. J. Chem. Eng. Data 2007, 52, 286-290. [CrossRef]

39. Steele, W.V.; Chirico, R.D.; Knipmeyer, S.E.; Nguyen, A. The thermodynamic properties of 2-aminobiphenyl. J. Chem. Thermodyn. 1991, 23, 957-977. [CrossRef]

40. Zaitsau, D.H.; Emel'yanenko, V.N.; Pimerzin, A.A.; Verevkin, S.P. Benchmark properties of biphenyl as a liquid organic hydrogen carrier: Evaluation of thermochemical data with complementary experimental and computational methods. J. Chem. Thermodyn. 2018, 122, 1-12. [CrossRef]

41. Varushchenko, R.M.; Efimova, A.A.; Druzhinina, A.I.; Tkachenko, E.S.; Nesterov, I.A.; Nesterova, T.N.; Verevkin, S.P. The heat capacities and thermodynamic functions of 4-methylbiphenyl and 4-tert-butylbiphenyl. J. Chem. Thermodyn. 2010, 42, 1265-1272. [CrossRef]

42. Chirico, R.D.; Steele, W.V.; Kazakov, A.F. Thermodynamic properties of 1-phenylnaphthalene and 2-phenylnaphthalene. J. Chem. Thermodyn. 2014, 73, 241-254. [CrossRef]

43. Ribeiro da Silva, M.A.V.; Matos, M.A.R.; Rio, C.A.; Morais, V.M.F.; Wang, J.; Nichols, G.; Chickos, J.S. A Thermochemical and Theoretical Study of the Phenylpyridine Isomers. J. Phys. Chem. A 2000, 104, 1774-1778. [CrossRef]

44. Emel'yanenko, V.N.; Zaitsau, D.H.; Pimerzin, A.A.; Verevkin, S.P. N-phenyl-carbazole as a potential liquid organic hydrogen carrier: Thermochemical and computational study. J. Chem. Thermodyn. 2019, 132, 122-128. [CrossRef]

45. Lipkind, D.; Hanshaw, W.; Chickos, J.S. Hypothetical Thermodynamic Properties. Subcooled Vaporization Enthalpies and Vapor Pressures of Polyaromatic Heterocycles and Related Compounds. J. Chem. Eng. Data 2009, 54, 2930-2943. [CrossRef]

46. Verevkin, S.P.; Turovtsev, V.V.; Andreeva, I.V.; Orlov, Y.D.; Pimerzin, A.A. Webbing a network of reliable thermochemistry around lignin building blocks: Tri-methoxy-benzenes. RSC Adv. 2021, 11, 10727-10737. [CrossRef]

47. Verevkin, S.P.; Konnova, M.E.; Turovtsev, V.V.; Riabchunova, A.V.; Pimerzin, A.A. Weaving a Network of Reliable Thermochemistry around Lignin Building Blocks: Methoxy-Phenols and Methoxy-Benzaldehydes. Ind. Eng. Chem. Res. 2020, 59, 22626-22639. [CrossRef]

48. Benson, S.W. Thermochemical Kinetics. Methods for the Estimation of Thermochemical Data and Rate Parameters; John Wiley \& Sons, Inc.: New York, NY, USA, 1968.

49. Verevkin, S.P.; Emel'yanenko, V.N.; Diky, V.; Muzny, C.D.; Chirico, R.D.; Frenkel, M. New Group-Contribution Approach to Thermochemical Properties of Organic Compounds: Hydrocarbons and Oxygen-Containing Compounds. J. Phys. Chem. Ref. Data 2013, 42, 033102. [CrossRef] 
50. Verevkin, S.P.; Zaitsau, D.H.; Emel'yanenko, V.N.; Yermalayeu, A.V.; Schick, C.; Liu, H.; Maginn, E.J.; Bulut, S.; Krossing, I.; Kalb, R. Making Sense of Enthalpy of Vaporization Trends for Ionic Liquids: New Experimental and Simulation Data Show a Simple Linear Relationship and Help Reconcile Previous Data. J. Phys. Chem. B 2013, 117, 6473-6486. [CrossRef] [PubMed]

51. Ribeiro da Silva, M.A.V.; Matos, M.A.R.; Amaral, L.M.P.F. Standard enthalpies of formation and of sublimation of 2,6dimethylquinoline and 2,7-dimethylquinoline. J. Chem. Thermodyn. 1995, 27, 1141-1145. [CrossRef]

52. Wheeler, S.E.; Houk, K.N.; Schleyer, P.v.R.; Allen, W.D. A Hierarchy of Homodesmotic Reactions for Thermochemistry. J. Am. Chem. Soc. 2009, 131, 2547-2560. [CrossRef] [PubMed]

53. Emel'yanenko, V.N.; Zaitseva, K.V.; Agapito, F.; Martinho Simões, J.A.; Verevkin, S.P. Benchmark thermodynamic properties of methylanisoles: Experimental and theoretical study. J. Chem. Thermodyn. 2015, 85, 155-162. [CrossRef]

54. Zaitseva, K.V.; Emel'yanenko, V.N.; Agapito, F.; Pimerzin, A.A.; Varfolomeev, M.A.; Verevkin, S.P. Benchmark thermochemistry of methylbenzonitriles: Experimental and theoretical study. J. Chem. Thermodyn. 2015, 91, 186-193. [CrossRef]

55. Pedley, J.B.; Naylor, R.D.; Kirby, S.P. Thermochemical Data of Organic Compounds, 2nd ed.; Chapman \& Hall: London, UK, 1986; ISBN 0412271001.

56. Allinger, N.L.; Yuh, Y.H.; Lii, J.H. Molecular mechanics. The MM3 force field for hydrocarbons. 1. J. Am. Chem. Soc. 1989, 111, 8551-8566. [CrossRef]

57. Petersson, G.A.; Bennett, A.; Tensfeldt, T.G.; Al-Laham, M.A.; Shirley, W.A.; Mantzaris, J. A complete basis set model chemistry. I. The total energies of closed-shell atoms and hydrides of the first-row elements. J. Chem. Phys. 1988, 89, 2193-2218. [CrossRef]

58. Konnova, M.E.; Vostrikov, S.V.; Pimerzin, A.A.; Verevkin, S.P. Thermodynamic analysis of hydrogen storage: Biphenyl as affordable liquid organic hydrogen carrier (LOHC). J. Chem. Thermodyn. 2021, 159, 106455. [CrossRef]

59. Müller, K.; Stark, K.; Emel'yanenko, V.N.; Varfolomeev, M.A.; Zaitsau, D.H.; Shoifet, E.; Schick, C.; Verevkin, S.P.; Arlt, W. Liquid Organic Hydrogen Carriers: Thermophysical and Thermochemical Studies of Benzyl- and Dibenzyl-toluene Derivatives. Ind. Eng. Chem. Res. 2015, 54, 7967-7976. [CrossRef]

60. Verevkin, S.P.; Emel'yanenko, V.N.; Heintz, A.; Stark, K.; Arlt, W. Liquid Organic Hydrogen Carriers: An Upcoming Alternative to Conventional Technologies. Thermochemical Studies. Ind. Eng. Chem. Res. 2012, 51, 12150-12153. [CrossRef]

61. Konnova, M.E.; Li, S.; Bösmann, A.; Müller, K.; Wasserscheid, P.; Andreeva, I.V.; Turovtzev, V.V.; Zaitsau, D.H.; Pimerzin, A.A.; Verevkin, S.P. Thermochemical Properties and Dehydrogenation Thermodynamics of Indole Derivates. Ind. Eng. Chem. Res. 2020, 59, 20539-20550. [CrossRef]

62. Emel'yanenko, V.N.; Varfolomeev, M.A.; Verevkin, S.P.; Stark, K.; Müller, K.; Müller, M.; Bösmann, A.; Wasserscheid, P.; Arlt, W. Hydrogen Storage: Thermochemical Studies of N -Alkylcarbazoles and Their Derivatives as a Potential Liquid Organic Hydrogen Carriers. J. Phys. Chem. C 2015, 119, 26381-26389. [CrossRef] 